\title{
Ethnobotanical study on wild edible plants used by three trans-boundary ethnic groups in Jiangcheng County, Pu'er, Southwest China
}

Yilin $\mathrm{CaO}^{1+}$, Ren $\mathrm{Li}^{2,33^{*+}} \mathbb{D}$, Shishun Zhou ${ }^{2}$, Liang Song ${ }^{4}$, Ruichang Quan ${ }^{2}$ and Huabin $\mathrm{Hu}^{5^{*}}$

\begin{abstract}
Background: Dai, Hani, and Yao people, in the trans-boundary region between China, Laos, and Vietnam, have gathered plentiful traditional knowledge about wild edible plants during their long history of understanding and using natural resources. The ecologically rich environment and the multi-ethnic integration provide a valuable foundation and driving force for high biodiversity and cultural diversity in this region. However, little study has uncovered this unique and attractive culture to the world.
\end{abstract}

Methods: We conducted ethnobotanical survey in 20 villages of Jiangcheng County from 2016 to 2020. Altogether 109 local Dai, Hani, and Yao people were interviewed, and their traditional knowledge about wild edible plants was recorded. Voucher specimens were identified by the authors and deposited in the herbarium of Xishuangbanna Tropical Botanical Garden, Chinese Academy of Sciences (HITBC). The use value was used as a quantitative index to evaluate the consumption frequency and relative importance of the wild edible plants. The Jaccard index was calculated to assess the usage similarity of different areas. The relationship of age and recognized wild edible plants by different ethnic people was performed by $\mathrm{R}$.

Results: A total of 211 wild edible plants, belonging to 71 families and 151 genera, were recorded. These plants were consumed as wild edible vegetables, seasonal fruits, salads, spices, sour condiments, tonic soups, tea substitutes, liquor brewing, or dyeing materials. The use value (UV), current cultivation, market availability, and the quantitative traditional knowledge inheritance situation of these wild edible plants among different generations, were analyzed. Based on the data from the threatened species list of China's higher plants and the IUCN Red List, the food plant list for Asia Elephant, the Subject Database of China Plant, and the calculated UV score, the top 30 most important wild edible plants were selected for further cultivation in some local villages.

(Continued on next page)

\footnotetext{
* Correspondence: liren@xtbg.ac.cn; huhb@xtbg.ac.cn

${ }^{\dagger}$ Yilin Cao and Ren Li contributed equally to this work.

${ }^{2}$ Southeast Asia Biodiversity Research Institute, Chinese Academy of Sciences

\& Center for Integrative Conservation, Xishuangbanna Tropical Botanical

Garden, Chinese Academy of Sciences, Mengla 666303, Yunnan, China

${ }^{5}$ CAS Key Laboratory of Tropical Plant Resources and Sustainable Use,

Xishuangbanna Tropical Botanical Garden, Chinese Academy of Sciences,

Mengla 666303, Yunnan, China

Full list of author information is available at the end of the article
}

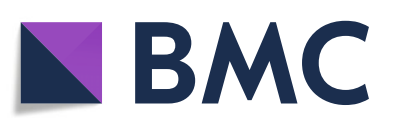

( ) The Author(s). 2020 Open Access This article is licensed under a Creative Commons Attribution 4.0 International License, which permits use, sharing, adaptation, distribution and reproduction in any medium or format, as long as you give appropriate credit to the original author(s) and the source, provide a link to the Creative Commons licence, and indicate if changes were made. The images or other third party material in this article are included in the article's Creative Commons licence, unless indicated otherwise in a credit line to the material. If material is not included in the article's Creative Commons licence and your intended use is not permitted by statutory regulation or exceeds the permitted use, you will need to obtain permission directly from the copyright holder. To view a copy of this licence, visit http://creativecommons.org/licenses/by/4.0/. The Creative Commons Public Domain Dedication waiver (http://creativecommons.org/publicdomain/zero/1.0/) applies to the data made available in this article, unless otherwise stated in a credit line to the data. 


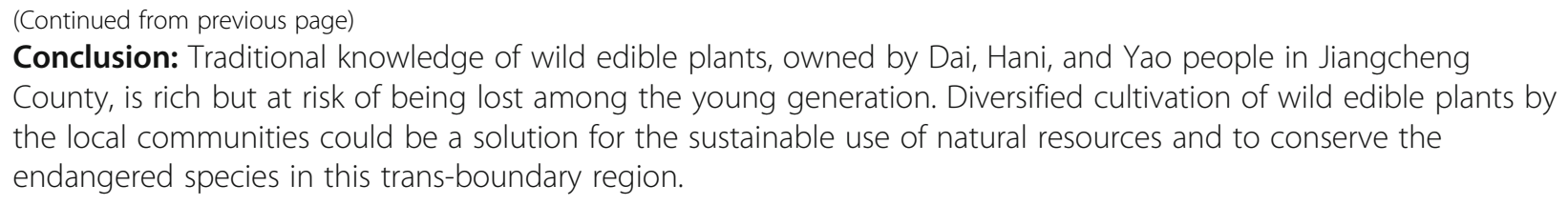

Keywords: Wild edible plants, Trans-boundary ethnic groups, Traditional knowledge, Conservation and sustainable use, Jiangcheng County

\section{Background}

Southeast Asia, including Southwest China, is one of the 34 biodiversity hotspots for conservation priorities in the world [1]. The international borders are essential habitat for the survival of many endangered species. Asia contains approximately $82 \%$ of the global border hotspots (the richest $5 \%$ of border segments) for threatened trans-boundary species, and the distribution of threatened species with trans-boundary ranges is concentrated primarily in Southeast Asia [2]. China shares $1852 \mathrm{~km}$ of border with Laos and Vietnam, and there are around 15 cross-border ethnic groups living in this trans-boundary region, with Dai, Hani, and Yao people as three main indigenous groups $[3,4]$. Known as a "green pearl" on the Tropic of Cancer in Yunnan, China, Pu'er City is selected as a key conservation area because of its important biodiversity status in Yunnan and even in China [5]. Jiangcheng county, belonging to Pu'er City and located in Southwest China, is the only Chinese county bordered by three countries (China, Laos, and Vietnam). Jiangcheng county was named after its three surrounding rivers and was part of the ancient Ailao Kingdom about 2100 years ago [6]. Geographically, it is situated in the Hengduan Mountain range, lying at the end of Wuliang Mountain with elevation ranging from 317 to $2207 \mathrm{~m}$. It is also a multi-ethnically inhabited region with 25 ethnic groups [7]. All of these make Jiangcheng County a microcosm of the rich bio-cultural kingdom in the transboundary regions among China, Laos, and Vietnam.

Wild edible plants, such as vegetables and fruits, play an important role in our daily life. Wild vegetables are favored by more and more people because they have fresh and aromatic taste, rich mineral nutrients, pollution-free growing environment, strong vitality, and high medicinal and human health benefits $[8,9]$. Wild edible plants are important in many facets of life for many indigenous and agricultural communities [10-12]. They could provide supplement food, nutrients, medicines, building materials, firewood, dyes, staple, and cash income to native ethnic groups [13-17]. Settled in the low mountain land and faraway from big modern cities, the local people in Jiangcheng County rely a lot on the natural products from the wild. In the past, wild edible plants were mostly self-harvested and consumed as main food substitutes by the local people. Nowadays, wild edible plants are more likely to be sold in the markets for urban citizens and tourists. Thus, the local communities have gathered abundant traditional knowledge from these long-term practices. Previous studies of the wild edible plants in Southwest China focused on providing a list of species $[18,19]$. The traditional knowledge associated with the listed species as well as their quantitative inheritance information among different generations were absent from these studies.

Global climatic change poses a huge threat on biodiversity [20], and results in global biodiversity loss through drought and warming [21]. There are an estimated 500, 000 species of land plants and a third of all land plants are perhaps at risk of extinction due to habitat loss, fragmentation, and degradation, over-exploitation, invasive species, pollution, and anthropogenic climate change [22]. Current species extinction rates are higher than would be expected and the sixth mass extinction may be under way [23]. Besides, most of the residential ethnic groups in this region depend on the local forest for their livelihood. In addition to the poor economy and excessive collection of wild plants, large-scale rubber and other economic plantation, fragmentation, and a progressively decreased connectivity of forest aggravate the crisis on the sustainable use of the natural resources and the situation of biodiversity conservation in this region is worsening [24-27].

The traditional ecological knowledge, gathered by the indigenous communities in their long interaction with nature, is an important part of human cultural heritage. Much traditional ecological knowledge is under threat and at the verge of disappearing due to environmental changes, livelihood diversification, and the influence of cultural conflicts [28-31]. Meanwhile, the ethnic groups in this region do not have or do not use their own written language, and their traditional knowledge could only be inherited by the next generation through oral communication. Any loss can turn out to be permanent. Thus, the exploration and documentation of the local traditional knowledge of the wild edible plants in this region are of the utmost importance.

The aim of this study was to catalog the traditional knowledge on the wild edible plants used by three transboundary ethnic groups in Jiangcheng County, to quantify 
the inheritance of traditional knowledge, and to provide primary scientific practices for future sustainable utilization and conservation of wild edible plants.

\section{Methods}

\section{Study area}

Jiangcheng County is bordered by Laos and Vietnam, and its geographical coordinates are between longitudes $101^{\circ} 14^{\prime}-102^{\circ} 19^{\prime}$ east and latitude $22^{\circ} 20^{\prime}-22^{\circ} 36^{\prime}$ north with a subtropical humid climate. Its spring and autumn periods are longer than summer and winter with an average annual rainfall of $2189.3 \mathrm{~mm}$ and a comfortable average temperature of around $19.4^{\circ}$ [7]. During 20162020 , ethnobotanical studies on wild edible plants utilized by local people were carried out in 20 villages and nearby markets, distributed at all 6 townships of Jiangcheng County (Fig. 1). Zhengdong, one of township in Jiangcheng, has been recognized with one of the fourth batch of national beautiful and livable townships awards by the Chinese Ministry of Housing and Urban-Rural Development, and as an ecological civilization township by the Yunnan province. Zhengdong town is also an important habitat for around 44 Asian elephants [32]. Nine different villages of Zhengdong township, which are famous for multi-ethnic traditional culture and wellpreserved natural forest, were chosen for a detailed study. There is no frost and snow in the whole year, rich in heat resources and fertile land with corn, rice, rubber, tea, coffee, passion flower, nuts, bananas, and mangoes as the main economic crops [7]. Hani, Dai, and Yao people are the three major ethnic minorities that are living at China, Laos, and Vietnam trans-boundary region and have a long tradition and abundant practices of eating wild plants.

\section{Ethnobotanical survey}

Before ethnobotanical survey in each village, we had a meeting with the village head in which we explained our research objective. Consent from the village head and every interviewed villager was gained and all investigations were conducted following the ethical guidelines of the International Society of Ethnobiology [33]. Ethnobotanical field survey on wild edible plants consumed by three trans-boundary ethnic groups were carried out in 20 villages (13 Hani, 4 Dai, 3 Yao) during different seasons of 2016 to 2020 (Fig. 2). Multiple interdisciplinary methods, including key informant interview, semistructured interview, and direct observation were used in the survey [34] (Fig. 3). The main informants were introduced by the local village head at first, then recruited haphazardly during house-to-house questioning. A total of 109 informants, including 50 males and 59 females, with ages ranging from 21 to 78 years old, were interviewed. The " $5 \mathrm{~W}+\mathrm{H}$ " questions (i.e., questions concerning what, when, where, who/whom, why, and how the subjects utilize wild edible plants) $[34,35]$ were used to collect the local name, used parts, usage, preparation methods, function, richness, or availability information of the wild edible plants. The investigations of different markets nearby the village were also conducted to collect the selling and consumption information of wild edible plants in local peoples' daily life.

Interviews were carried out mainly in Mandarin, although ethnic languages were also used with assistance from local village heads or guides in the study sites. The

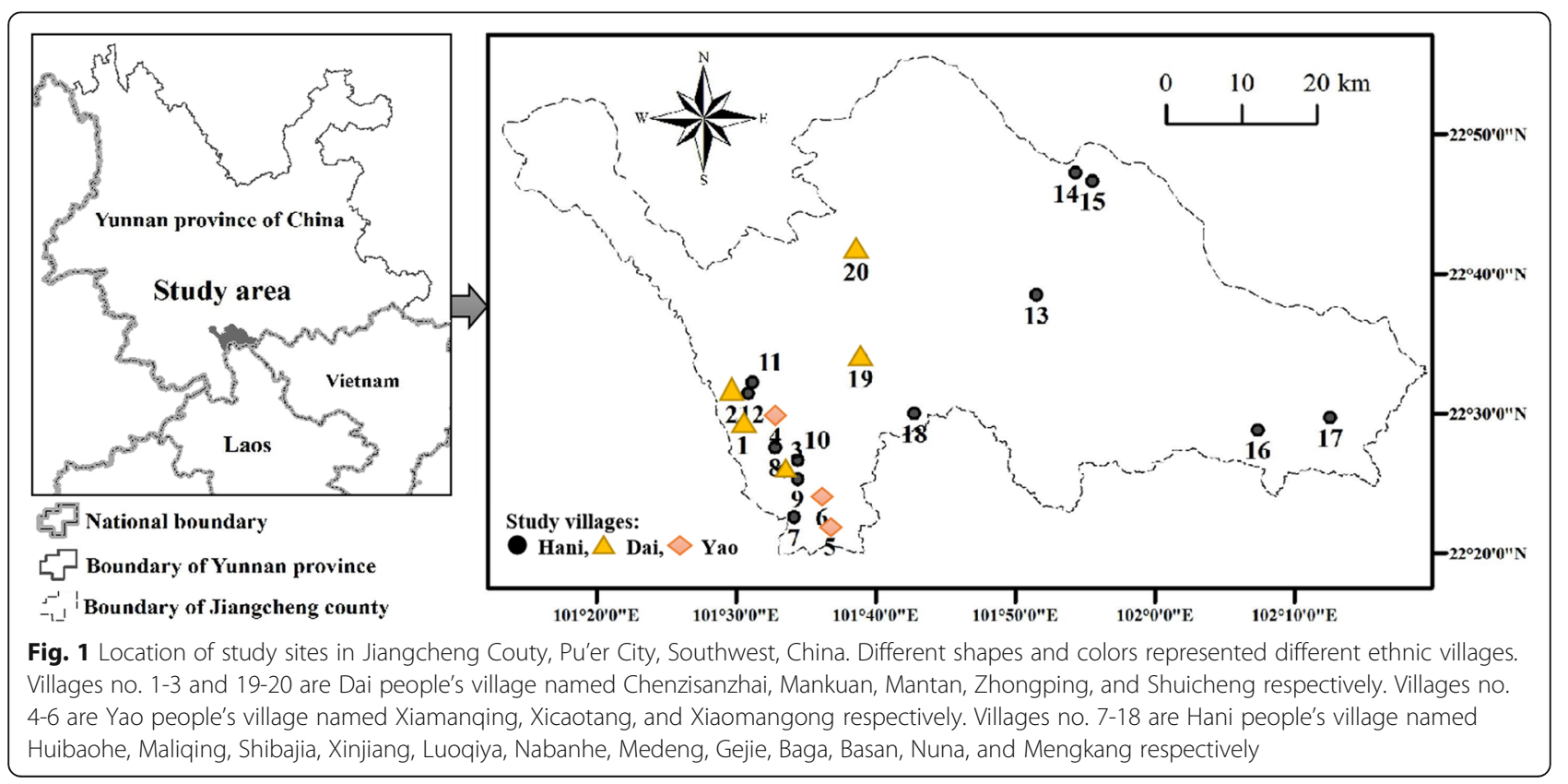



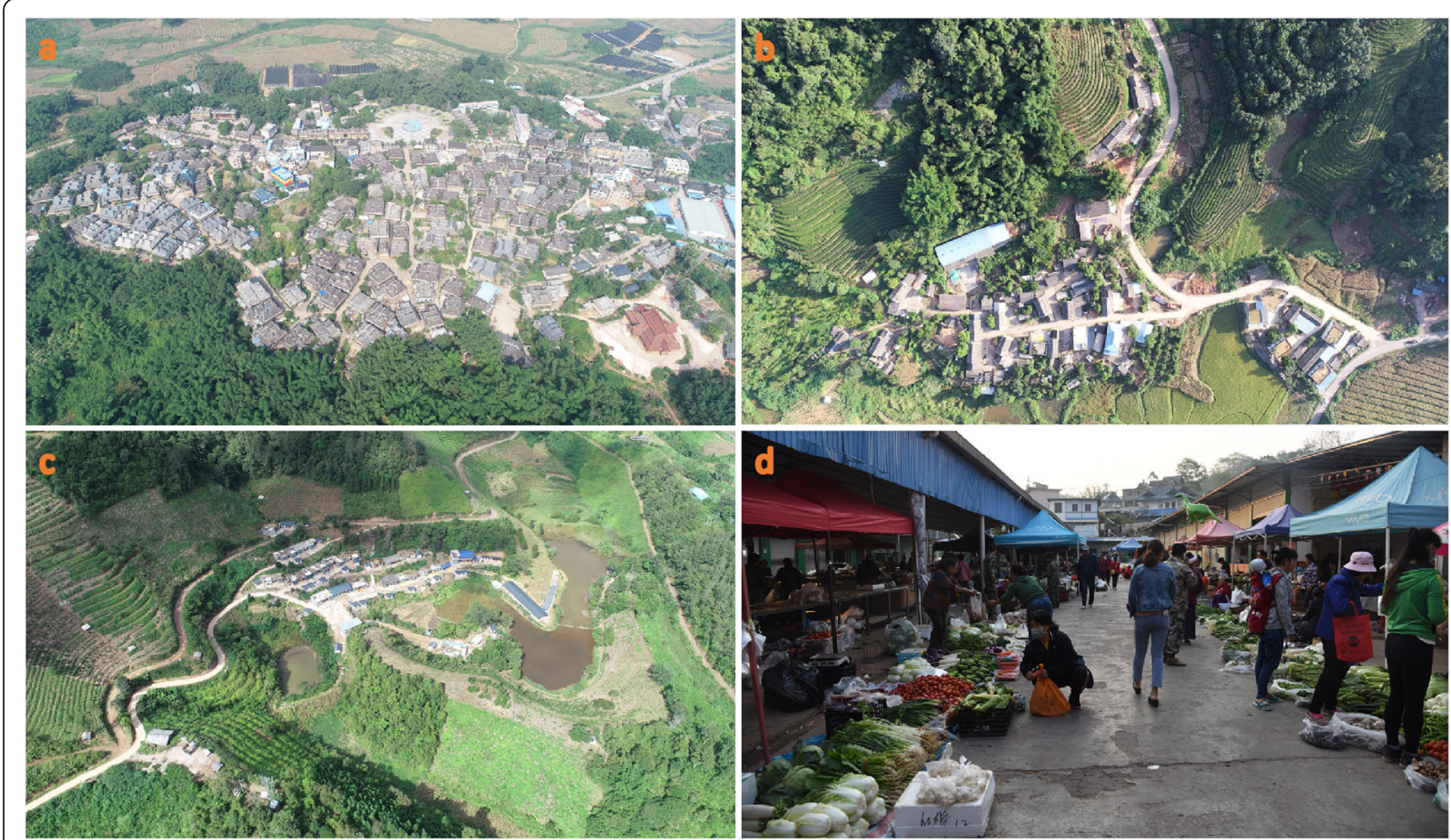

Fig. 2 Investigated Dai (a), Hani (b), Yao (c) village, and local market (d)

local names of wild edible plants were recorded by Chinese Pinyin. The collected voucher specimens were identified by the authors with reference to the flora of China and were deposited in the Herbarium of Xishuangbanna Tropical Botanical Garden, Chinese Academy of Sciences (HITBC). We adopted the APG IV system for the taxonomic definition of plant families and species [36]. The uniform nomenclature of plants was given by following the information in The Plant List [37]. The conservation status was recorded by referring to the data from IUCN Red List [38], threatened species list of China's higher plants [39], and the Subject Database of China Plant [40].

\section{Data analysis}

The use values (UV) of each wild edible plant were calculated to evaluate the relative importance of each plant based on the number of times cited and the number of informants $[35,41]$. The formula for $\mathrm{UV}$ is $\mathrm{UV}=\left(\sum U_{\mathrm{i}}\right) /$ $N$ [35]. $U_{\mathrm{i}}$ is the times cited by each informant for a certain wild edible plant, while $N$ is the total number of informants. The similarity or dissimilarity of plant species used in each pair of the ethnic communities studied was analyzed with the Jaccard index, $\mathrm{JI}=a /(a+b+c)$, where $a$ is the number of species in common; $b$ the number of species used only by one specific community, and $c$ is the number of species used only in the other community [42]. We used a spreadsheet (Excel) to make the catalog and analysis about the ethnobotanical information of wild edible plants. A uni-variate linear regression analysis was undertaken using $\mathrm{R}$ (version 4.0.2) to evaluate the relationship of informants' age and the number of mentioned wild edible plants. Significant difference was accepted at $P<0.05$.

\section{Results and discussion}

Diversity of wild edible plants, life forms, and edible parts in Jiangcheng County

Local people in Jiangcheng County do not have a very strict taxonomy system, and they treat all the plants that are not grown or cultivated in their farm lands or collected from the forest or mountain areas as wild edible plants. A total of 211 wild edible plants, including one feral species Colocasia esculenta "Tonoimo", along with ethnobotanical catalog information such as scientific names, family names, local names, life forms, edible parts, usage and preparations, voucher numbers, cultivation and market status, were recorded (Table 1). The 211 species, belonging to 71 families and 151 genera, account for about $20.2 \%, 9.0 \%$, and $3.8 \%$ of the total families, genera, and species of high plants in Pu'er City [5]. The most frequently used plants are mainly from the family of Poaceae (14 species), Fabaceae (12 species), Lamiaceae (11 species), Zingiberaceae (8 species), Araliaceae (7 species), Amaranthaceae (7 species), and Moraceae (7 species). At genus level, Dendrocalamus, Dioscorea, 


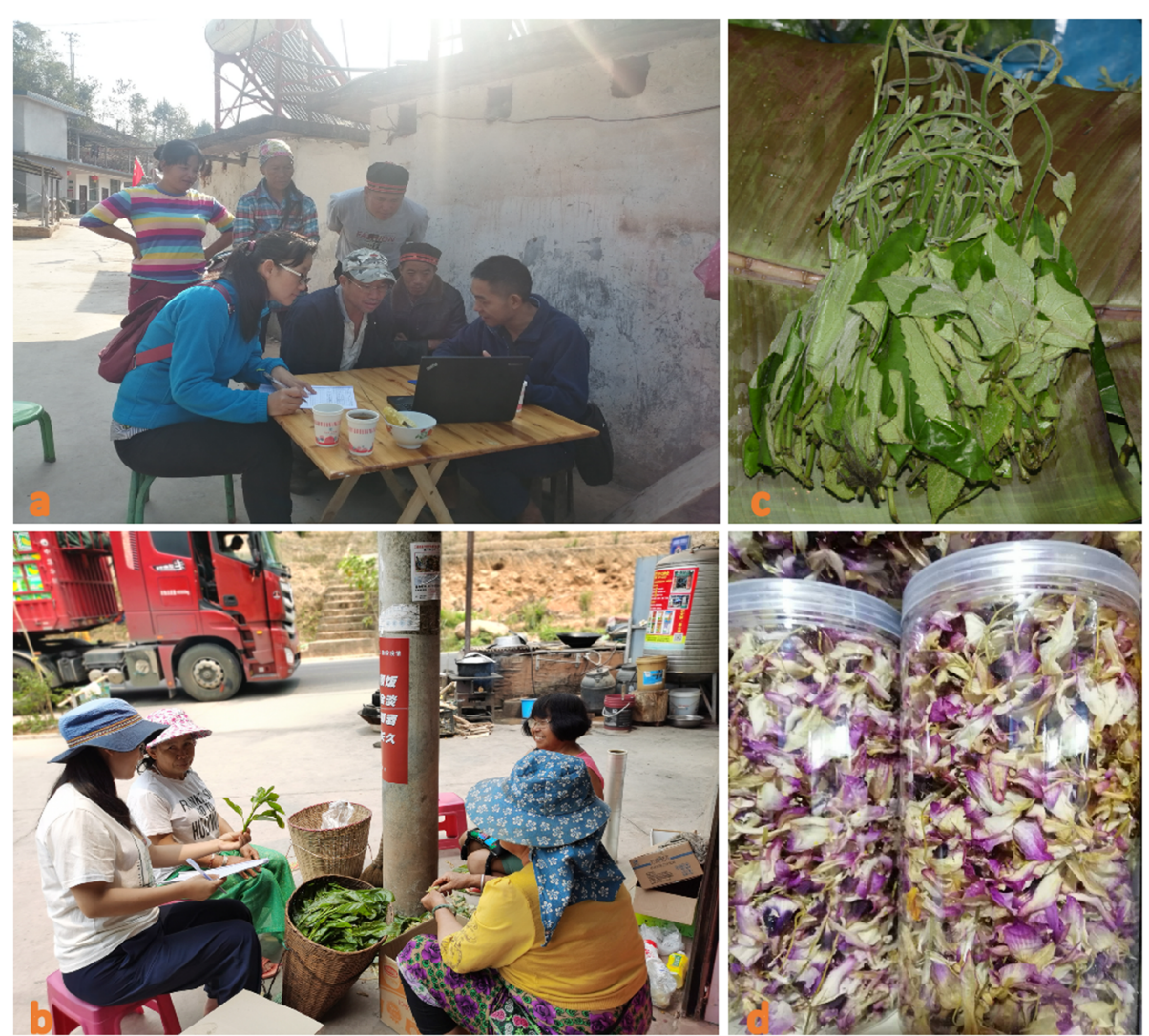

Fig. 3 Interviewing the local people $(\mathbf{a}, \mathbf{b})$, informed permissions from the local people have been obtained for the use of the pictures; Parabaena sagittata Miers (c) and Dendrobium nobile Lindl. (d) sold at the market

Solanum, Amaranthus, Amomum, Colocasia, Dendrobium, Ficus, Musa, and Zanthoxylum contain 4 to 6 species. There are 29 families and 119 genera that include only one species in the list. This is one of the longest list of local wild edible plants published, and reveals that this is a region of global significance for wild edible plant diversity.

Among the 211 species, there are 95 herb species (45.0\%), 54 trees (25.6\%), 38 vines (18.0\%), 13 shrubs (6.2\%), and 11 bamboos (5.2\%) (Table 2). All wild edible plants were also classified by their edible parts (Table 3 ). The most commonly consumed parts of the plant were tender stem and leaf (91 species, 43.1\%), fruit (50 species, $23.7 \%$ ), flower (29 species, 13.7\%), rhizome (15 species, $7.1 \%$ ), followed by root, bamboo shoot, young leaf, tender stem heart, stem, young shoot, seed, bark, petiole, and inflorescence (Table 3 ). The rich variety of edible parts collected from different life form species demonstrated that the local communities have gathered a lot of traditional knowledge from their daily consumption of wild edible plants. They could figure out which plant part is safe to eat and get rid of non-edible or poisonous parts. For example, the tuber of Colocasia (Araceae) plants, such as Colocasia esculenta (L.) Schott and
Colocasia fallax Schott, is mostly edible as coarse grains, vegetables, or pig feed [43], while the tuber of Colocasia gigantea (Blume) Hook. f. is extremely poisonous, not only to insects but also to people. Ingestion of this tuber by accident could cause severe pain in the esophagus and digestive system and the edible part of this plant is thus the petiole but not the tuber [44]. Moreover, many species provide more than two edible parts for the local people, this information could be interpreted as their preference for some species, and could also be useful for the further economic exploration of these wild edible plants.

\section{Diversity of usage and preparation methods}

As for the usage and preparation methods (Table 4), more than two-thirds of the plants were consumed as potherb (wild vegetables, 67.8\%). Potherbs are normally fried or boiled to make a mixed wild vegetable soup. Twenty-four species were used to make salad freshly or after boiling. Besides, 25 wild fruits were consumed as seasonal fruits with 3 of them also used for liquor brewing. The following usages are tonic soup, spice ingredient, sour condiment, liquor brewing, tea substitute, dye material, and nut. During our investigation, we found 


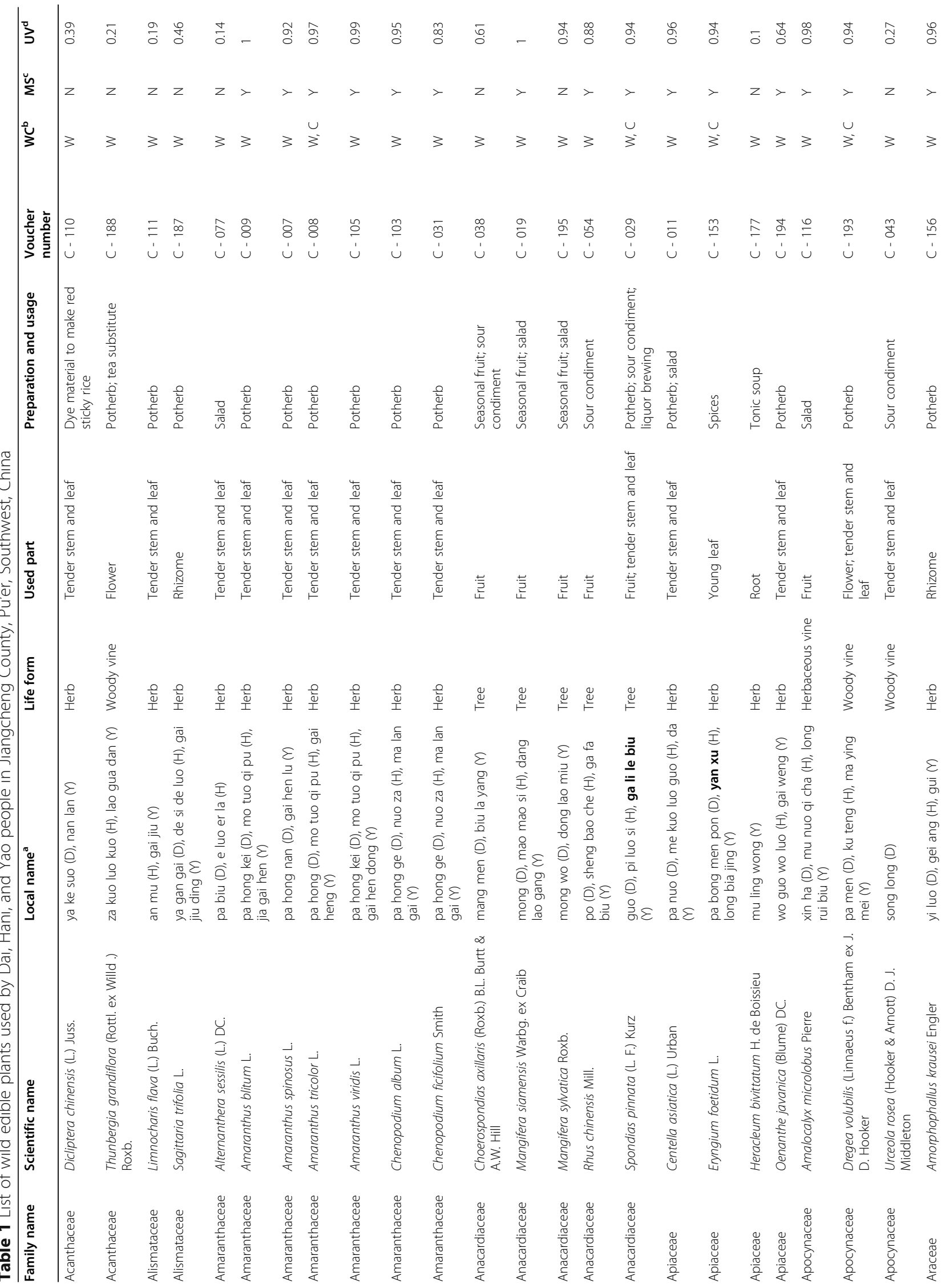




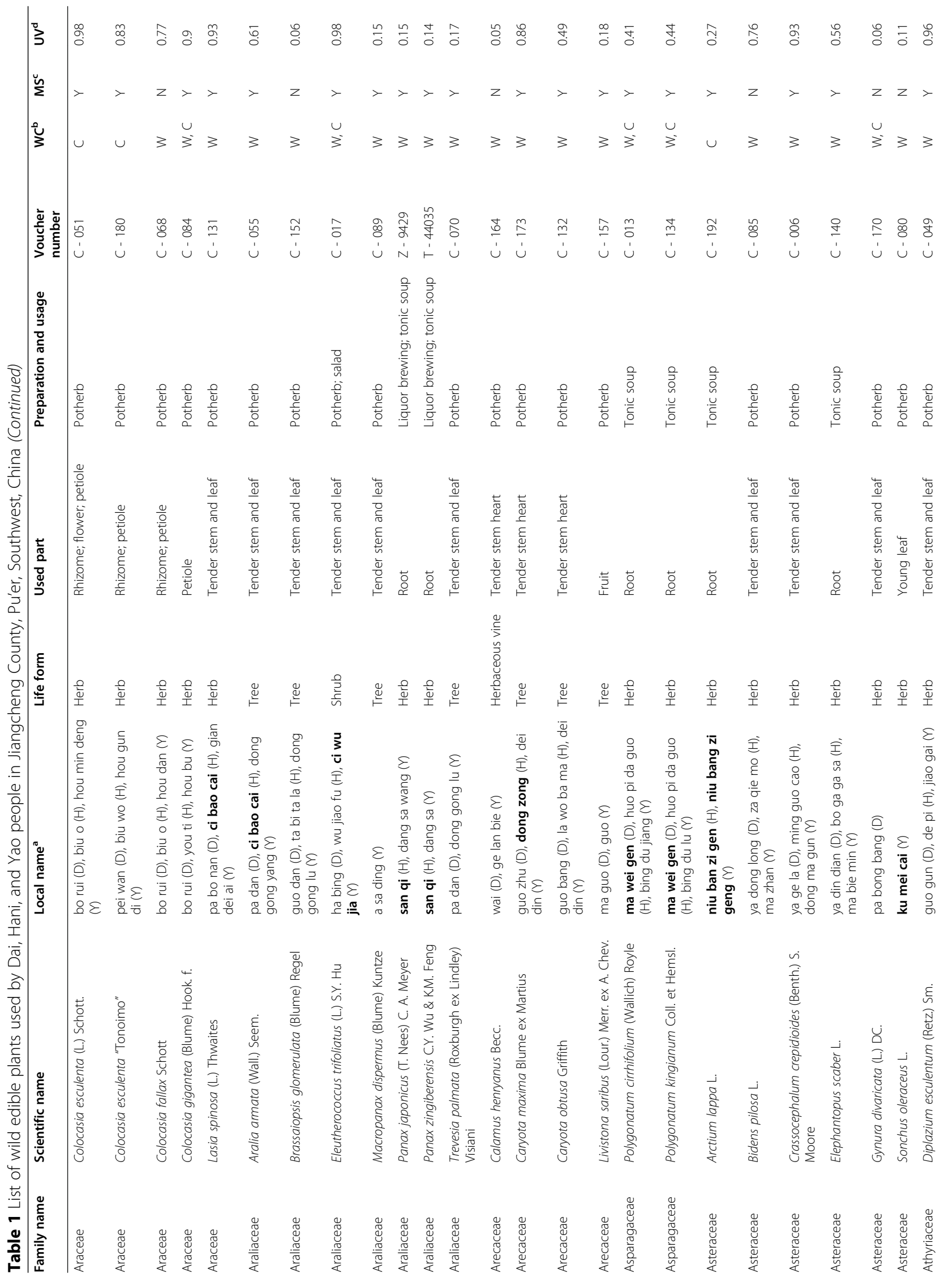




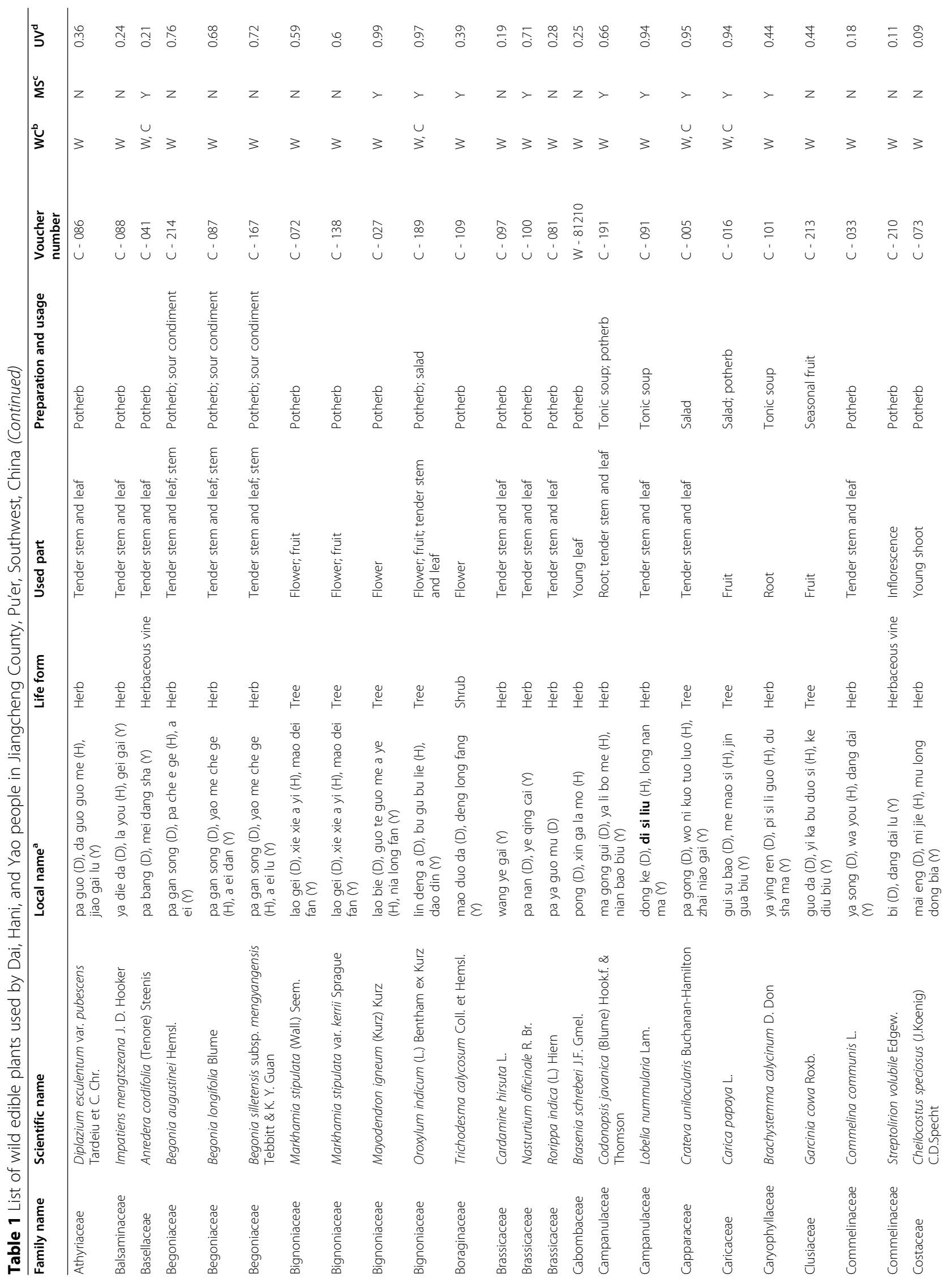




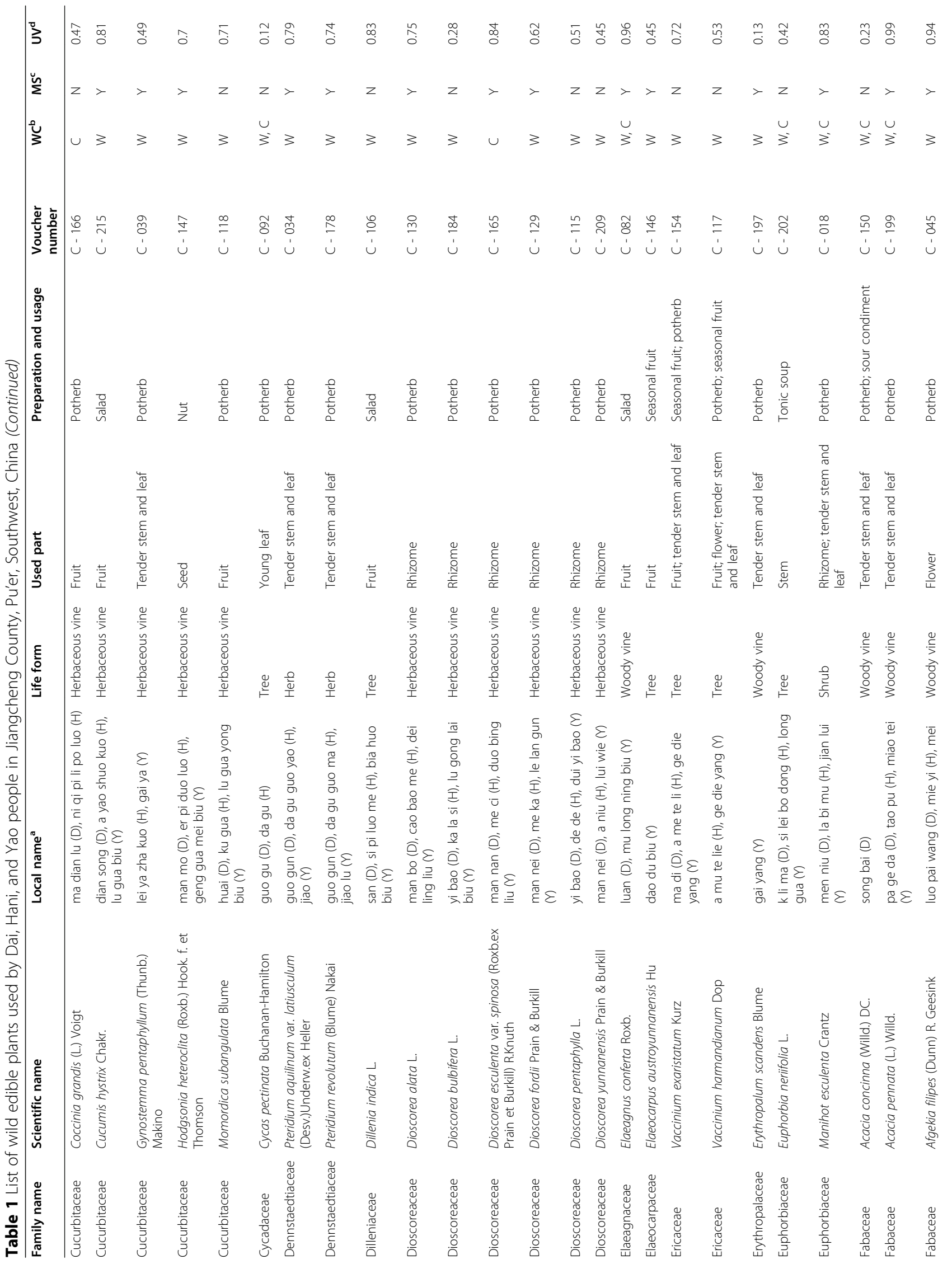




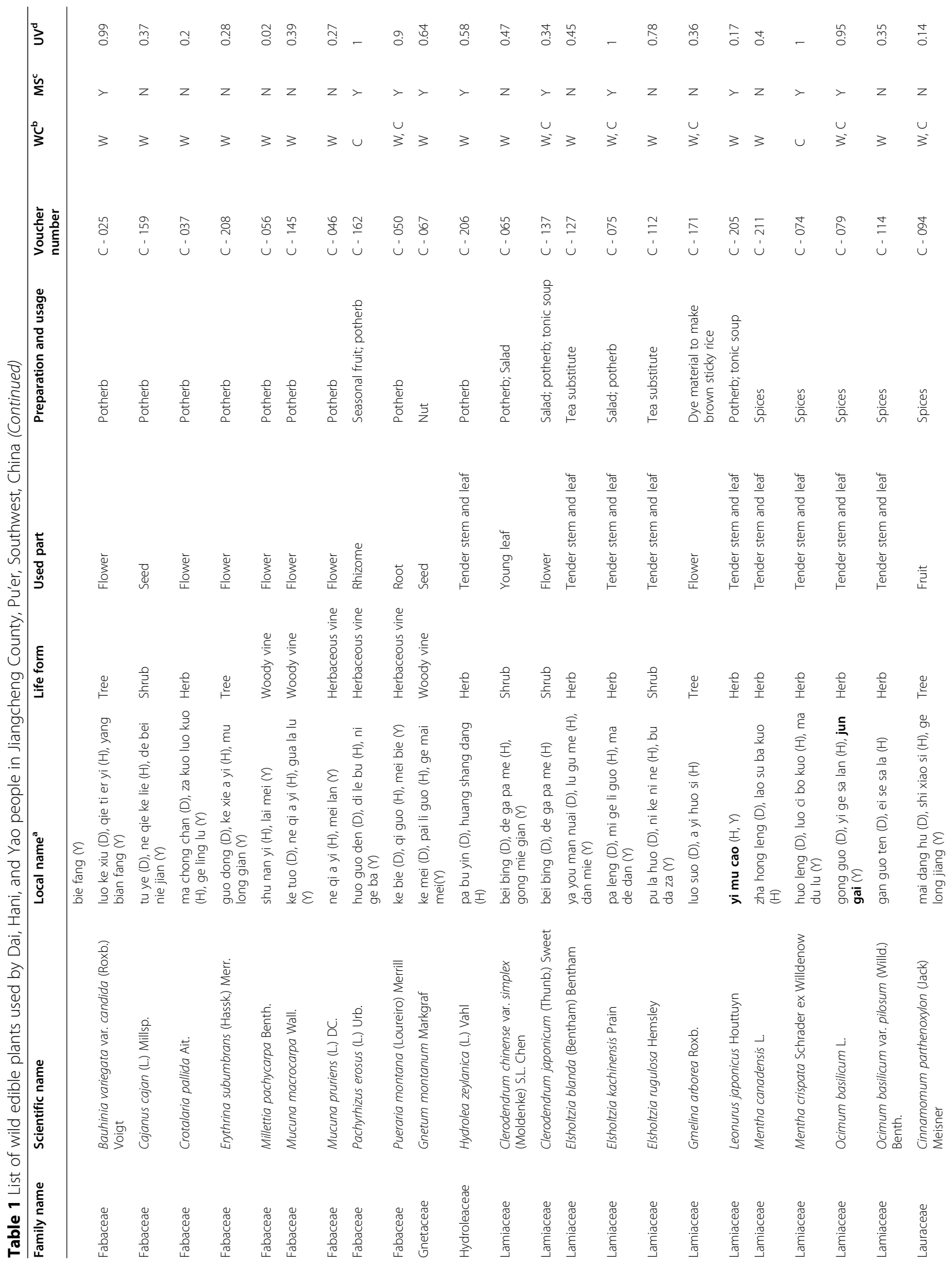




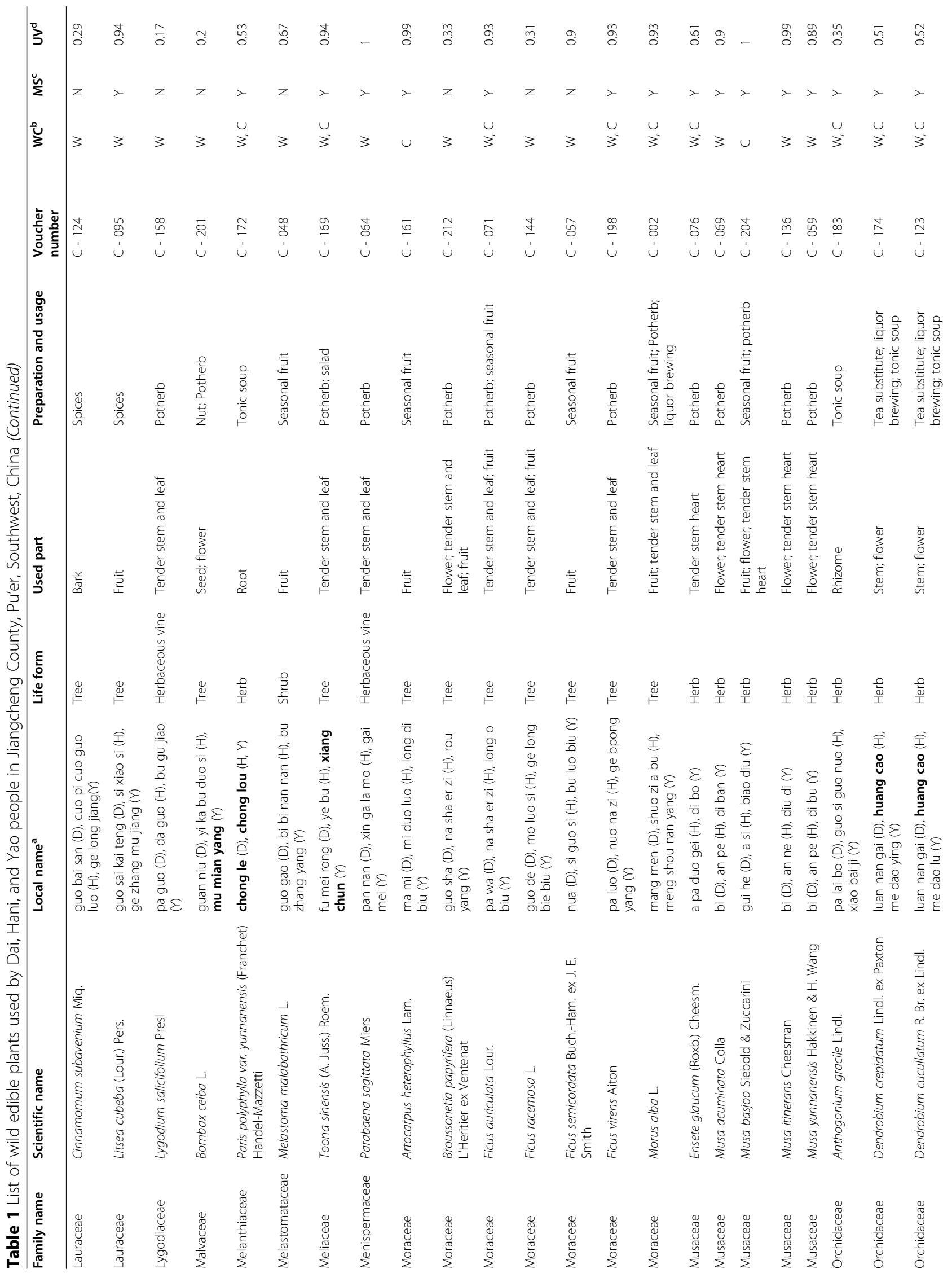




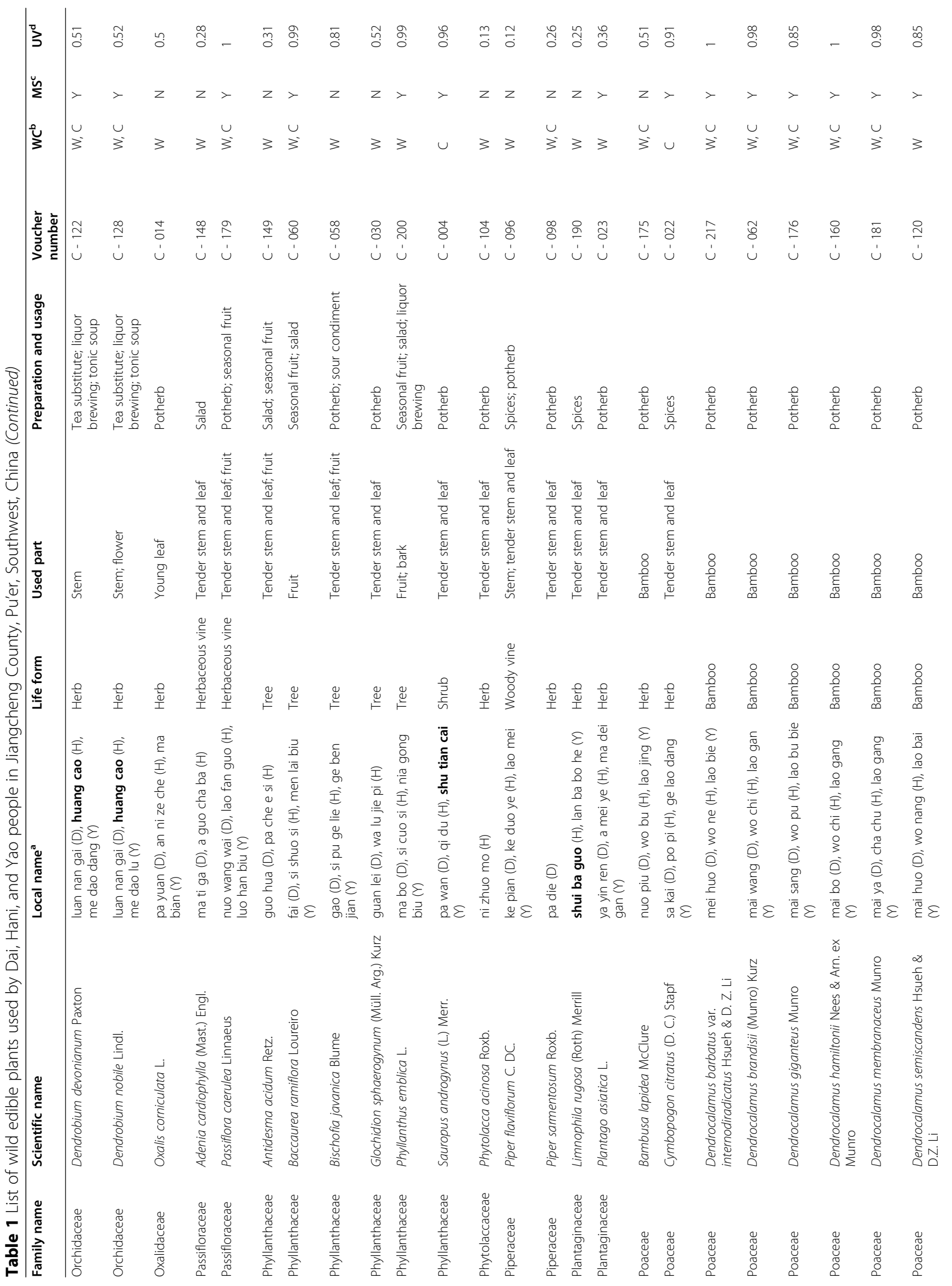




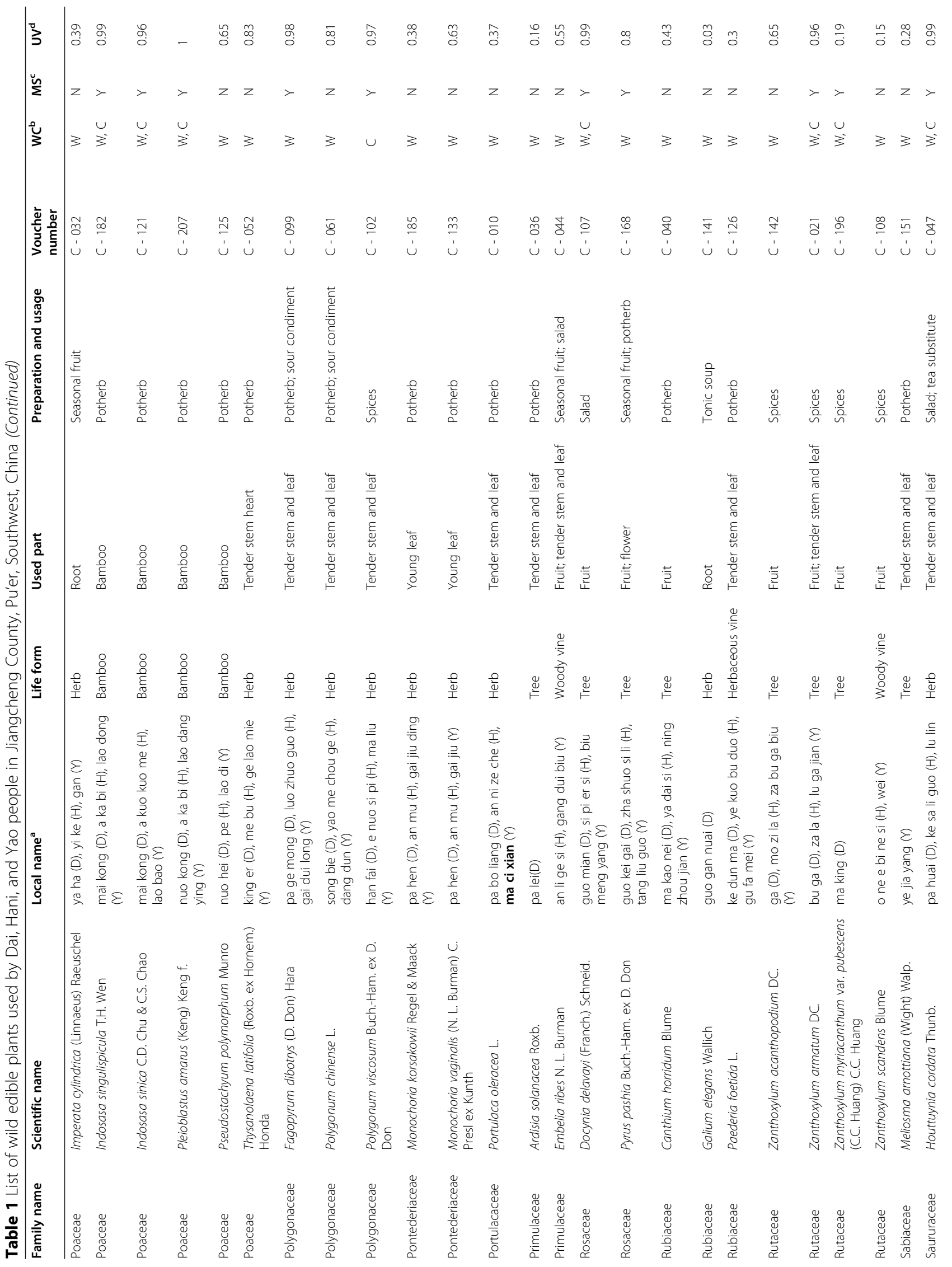




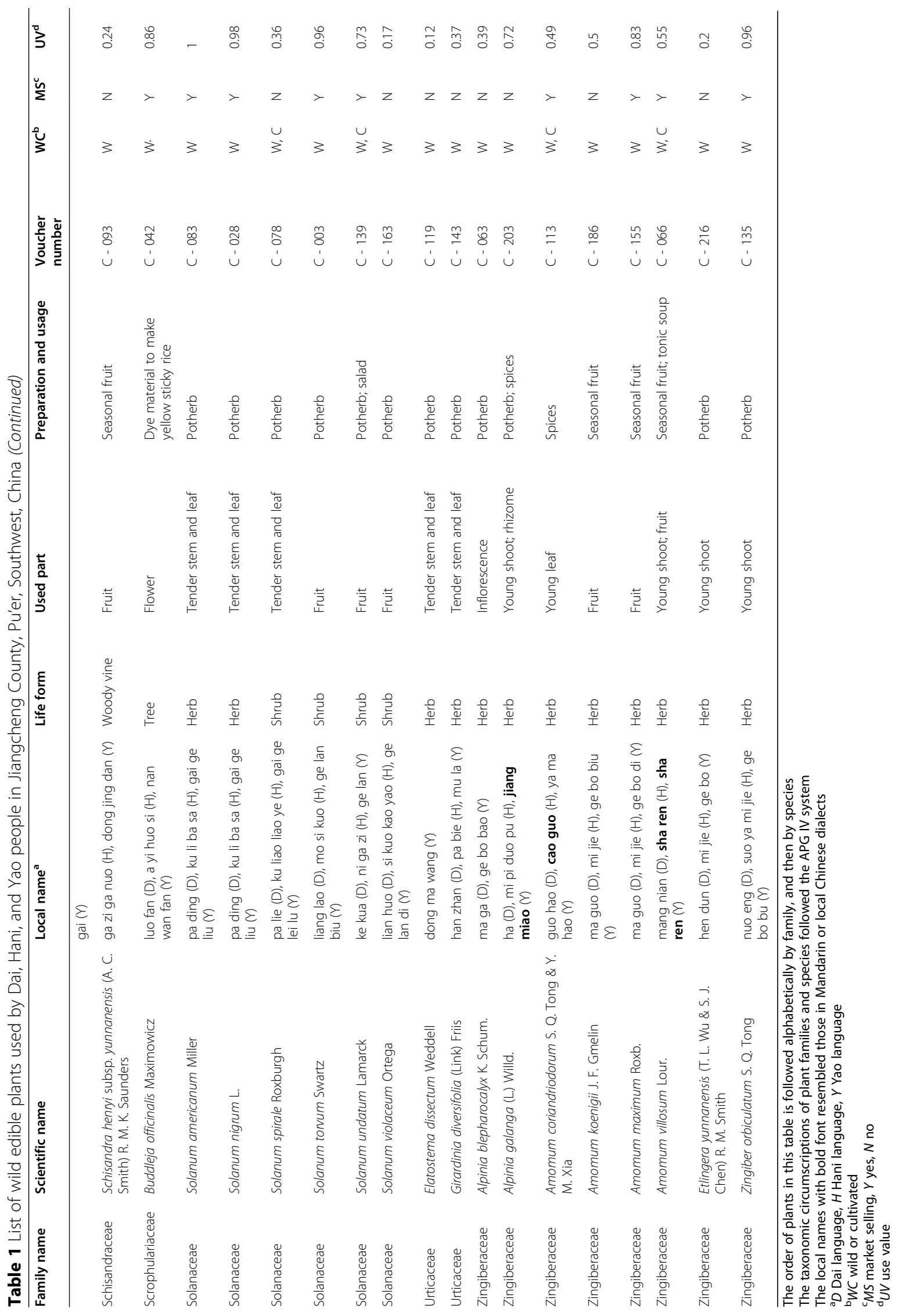


Table 2 Life forms of wild edible plants in Jiangcheng County

\begin{tabular}{lll}
\hline Life forms & Records & Percent (\%) \\
\hline Herb & 95 & 45.02 \\
Tree & 54 & 25.59 \\
Herbaceous vine & 23 & 10.90 \\
Woody vine & 15 & 7.11 \\
Shrub & 13 & 6.16 \\
Bamboo & 11 & 5.21 \\
\hline
\end{tabular}

that local people have some special taste preference for choosing the wild edible plants. For instance, there are 18 species, such as Litsea cubeba (Lour.) Pers., Zanthoxylum armatum DC., Zanthoxylum myriacanthum var. pubescens (C.C. Huang) C.C. Huang, Alpinia galanga (L.) Willd., and Amomum coriandriodorum S. Q. Tong \& Y. M. Xia, used as spice ingredients to cook beef or mutton, and 11 species, such as Spondias pinnata (L. F.) Kurz, Begonia augustinei Hemsl., and Urceola rosea (Hooker \& Arnott) D. J. Middleton, used as sour condiments to make fish or cook pork soup. Besides the spicy and sour tastes, several species from the Solanaceae and Bignoniaceae families are consumed for their bitter taste. Acacia pennata (L.) Willd., having strong bad egg smell, is also used to cook fish soup, mixed wild vegetable soup, or fried egg.

On one hand, wild edible plants provide essential source of food for local people, on the other hand, some of these plants are believed to have health benefits and are utilized as medicine and beverage by the local people in Jiangcheng County. In this study, there are 21 plants used to make tonic soup with chicken or pork. The indigenous villagers used 9 plants to make traditional liquor, which are also frequently consumed to treat stomach or

Table 3 Edible parts of wild edible plants in Jiangcheng County

\begin{tabular}{lll}
\hline Parts used & Records & Percent (\%) \\
\hline Tender stem and leaf & 91 & 43.13 \\
Fruit & 50 & 23.70 \\
Flower & 29 & 13.74 \\
Rhizome & 15 & 7.11 \\
Root & 13 & 6.16 \\
Bamboo shoot & 11 & 5.21 \\
Young leaf & 9 & 4.27 \\
Tender stem heart & 9 & 4.27 \\
Stem & 9 & 4.27 \\
Young shoot & 5 & 2.37 \\
Seed & 4 & 1.90 \\
Bark & 2 & 0.95 \\
Petiole & 2 & 1.90 \\
Inflorescence & 2 & 0.95 \\
\hline
\end{tabular}

Table 4 Usage and preparation methods of wild edible plants in Jiangcheng County

\begin{tabular}{lll}
\hline Preparation and use & Records & Percent (\%) \\
\hline Potherb & 143 & 67.77 \\
Salad & 24 & 11.37 \\
Seasonal fruit & 25 & 11.85 \\
Spice ingredient & 18 & 8.53 \\
Tonic soup & 21 & 9.95 \\
Sour condiment & 10 & 4.74 \\
Liquor brewing & 9 & 4.27 \\
Tea substitute & 7 & 3.32 \\
Dye material & 3 & 1.42 \\
Nut & 3 & 1.42 \\
\hline
\end{tabular}

inflammatory disease or to help them to have a healthy and strong body. In Pu'er City, there is a long traditional culture of harvesting and cooking herbal medicines with different meat to make some tonic soup. More than 100 species of medicinal plants were sold on the herb market in Pu'er City during the Dragon Boat Festival (Chinese Duan Wu festival) [45].

The diverse use and preparation methods of wild edible plants in Jiangcheng County indicate that the indigenous people have learned a lot of traditional knowledge about how to adapt well to their natural environment. Their strong connections with nature benefit them, not only by avoiding harmful materials but also providing better taste experiences. These traditional usage and preparation practices raised a wonderfully diversified cooking culture. With the increasing demand for a better and healthy daily life, the consumption of wild edible plants has been increasing and many of them have been collected from the field to serve at local restaurants. The practice of making edible medicinal soup meets the requirements of food nutrition and body health at the same time for the modern world, and attracts more tourists to have a stomach feast in Pu'er City. The traditional knowledge is also valuable for future use of wild edible and medicinal plants in the food industry.

\section{The use value and traditional knowledge distribution among different generations and ethnic groups}

The use values (UV) of each species were calculated to determine their relative importance to local communities (Table 1). Sixty-five species with the highest UV (0.90-1.00) were remarked as the most consumed wild edible plants in Jiangcheng County. The five different age groups of informants (50 males and 59 females) consumed 90 to 155 wild edible species (Fig. 4). Generally, male and female villagers eat similarly for the same age groups and the elder generation owns much more 


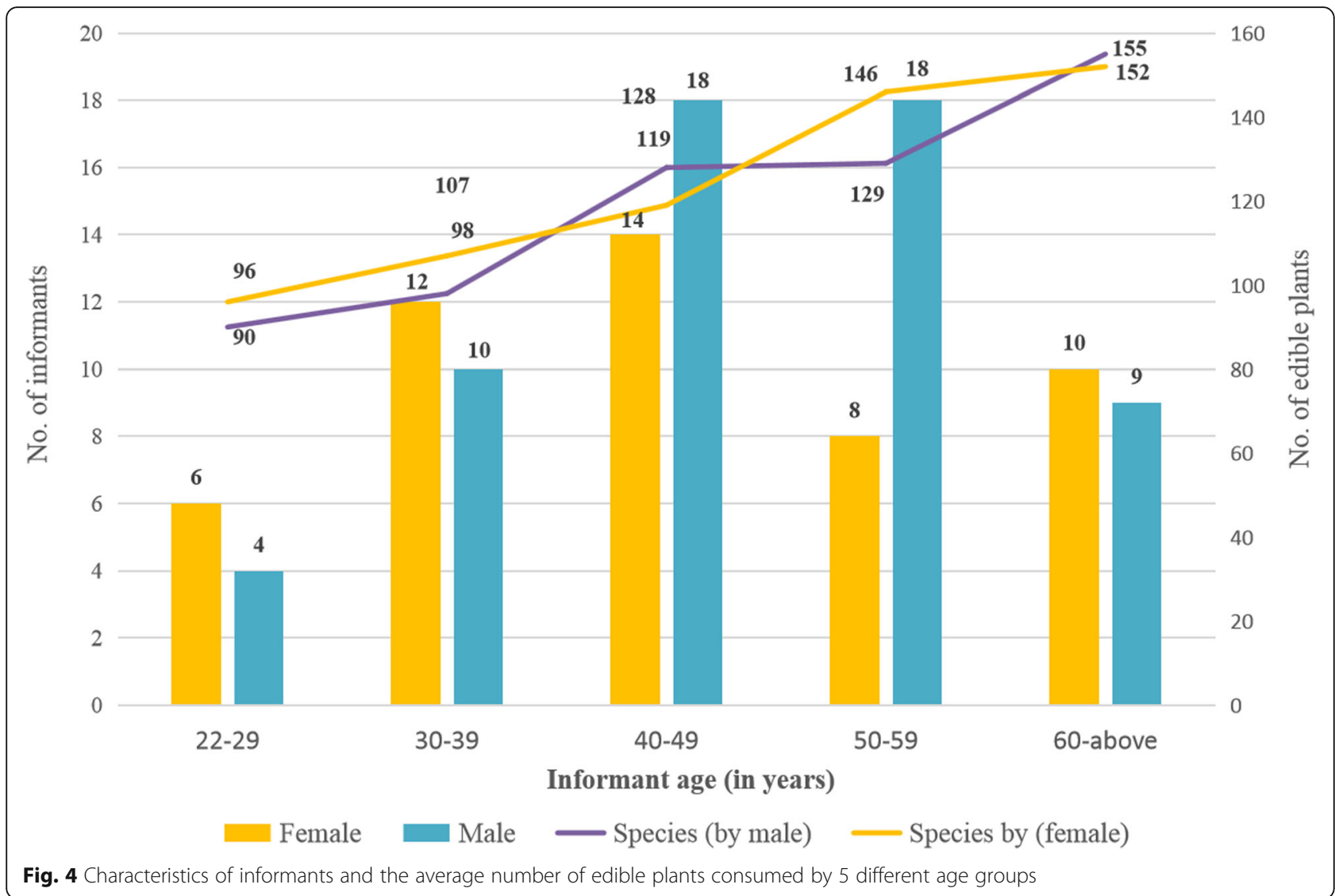

traditional knowledge than the younger generation. Based on the $t$ test and uni-variate linear regression, there is significant relationship between respondents' age and the number of wild edible plants identified (Fig. 5). A previous study showed that age had a positive effect on the number of listed wild food plants [46]. Our study found that, as we expected, the number of wild edible plants increased along with people's age. The traditional knowledge is under serious threats due to environmental degradation and acculturation, as well as biodiversity loss, and it showed signs of being forgotten and abandoned by the younger generation $[15,35]$. This situation is also occurring in Jiangcheng County. The traditional knowledge is handed down to successive generations. With the passing of elderly people, the increased deforestation of natural forest and monoculture of economic plants, and the decreased availability of wild edible plants, the traditional knowledge has high risk of loss among the younger generation in this trans-boundary region. Our study established a baseline for future work on the loss of traditional ecological knowledge among different generations.

Altogether, the local Dai, Hani, and Yao communities in this study consumed a total of 211 wild edible species. The number of wild edible species consumed by each group had a narrow range of 183 to 185 (Fig. 6) and as many as 149 species, accounting for $70.62 \%$ of the total wild edible species, were used by all 3 ethnic groups. The comparative analysis by Jaccard index (JI) showed that local Dai, Yao, and Hani communities shared very similar wild edible plants traditional knowledge, with JI values of $89.8 \%, 92.7 \%$, and $94.9 \%$ for Dai and Yao, Dai and Hani, and Yao and Hani respectively. This high similarity might be due to long terms of interactions and communication at similar geographic environment. The high JI values indicate that local people in this transboundary region are tightly connected and shared much traditional botanical knowledge with each other. Besides, the ethnic groups also learned some edible plants knowledge from the Han Chinese. For instance, there are 27 species, which are also commonly consumed by the Han Chinese as medicine or vegetable, and these plants' local names resemble those in Mandarin or local Chinese dialects (Table 1 ).

Searching around the neighboring areas, there were 284 wild edible species used by Dai, Hani, and Jinuo people in Xishuangbanna Dai Autonomous Prefecture [47] and 224 wild edible plants consumed by Hani people in Honghe Prefecture [35]. When contrasted with these neighboring areas, the wild edible species are quite different, with only 87 overlapping species between Jiangcheng County and Xishuangbanna, and 53 overlapping species for Jiangcheng 


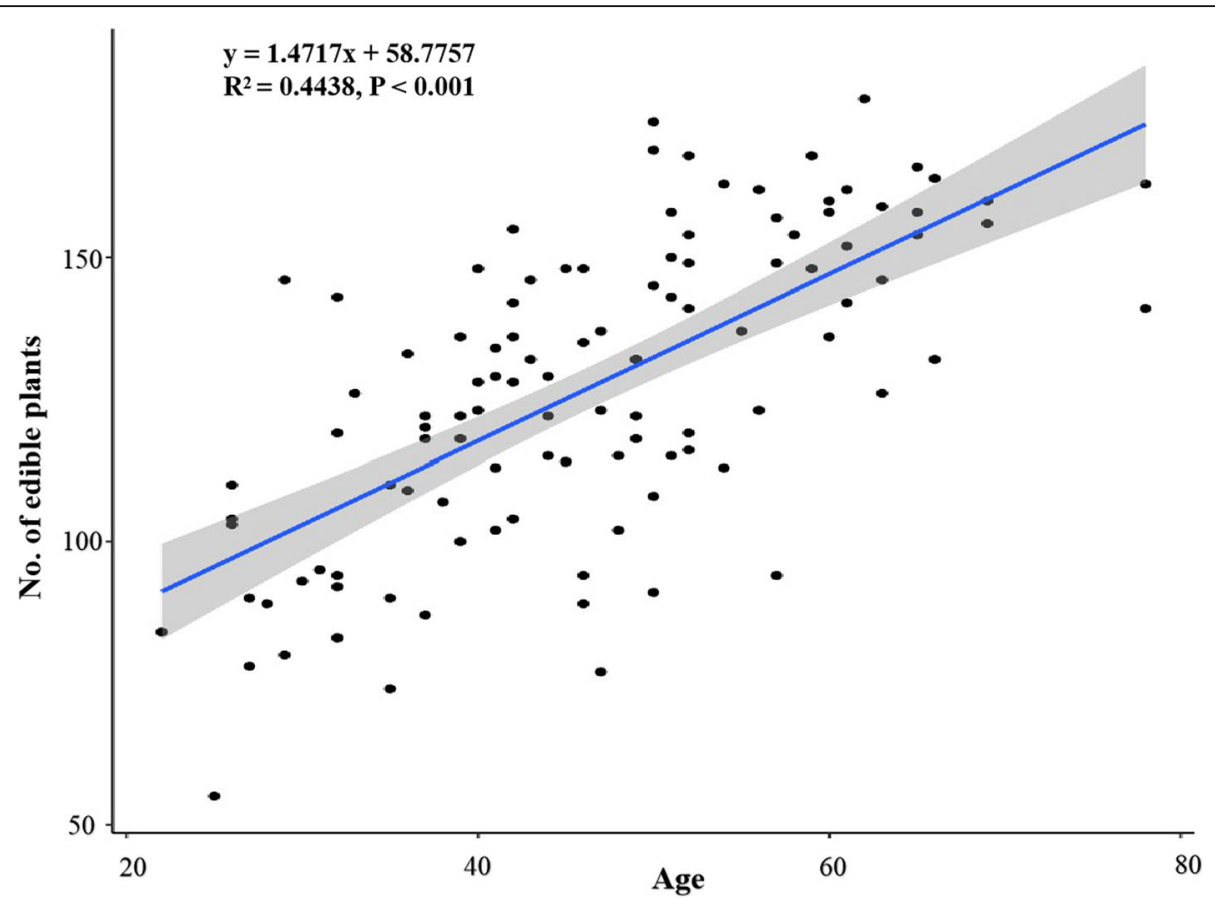

Fig. 5 The relationship of informants' age and the number of mentioned edible plants. In the formula, $y$ is the number of recognized edible plant, while $x$ is the age of villager

County and Honghe Prefecture respectively. This result shows that local people could always make a living from the limited circumstances and that the traditional knowledge of wild edible plants is tightly associated with the local environment. The Jaccard index (JI) values were calculated ranging from 13.9 to $21.3 \%$, suggesting that there

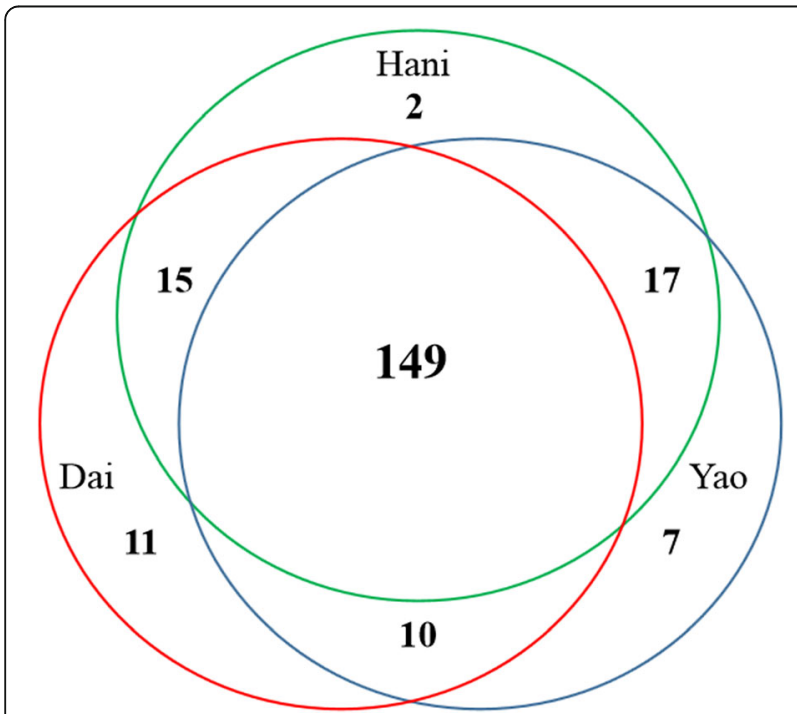

Fig. 6 Number of wild edible plants used in three ethnic groups. Red, green, and purple color represent Dai, Hani, and Yao people respectively has high diversity of wild edible plants among these biodiversity hotspot areas.

\section{Cultivation, market, and conservation status in the studied trans-boundary region}

Besides their abundant experiences about harvesting wild edible plants from forest, local Dai, Hani, and Yao people also have a very rich traditional knowledge of introduction and cultivation of wild plants. There are 68 plants cultivated by the local people in Jiangcheng County (Table 1). In the neighboring Xishuangbannan, Dai people have cultivated 315 plants in their villages, with 69 species used as medicines, fruits, vegetables, spices, horticultural flowers, and construction woods [48]. Seventy-nine kinds of folk utilizable plants of swidden agroecosystem that belong to 38 families and 64 genera were cultivated by Hani people, and used as firewood, food, fruit, fodder, beverage, condiment, and textile [49].

Wild edible plants not only supply the daily materials needed but also play an important role in ethnic groups' cash income. There are 117 wild edible plants sold at the local markets by the local people in Jiangcheng County (Table 1), and 146 wild vegetable species were found to be sold at the local markets and restaurants in Xishuangbanna [47]. On one hand, the huge market demands for wild edible plants contribute to thickening the wallet for the local people. On the other hand, it has been stimulating the increase of pressure on wild 
collection from the wild, with potential implications for biodiversity conservation. For instance, Panax zingiberensis C.Y. Wu \& K.M. Feng, which was cooked by the local people with chicken to produce healthy soup, and mixed with traditional wine to make tonic liquor, has already been listed as endangered species, and may need more conservation efforts to resolve this potential overharvesting pressure.

Habitat loss is another main threat to conserve the endangered or rare wild edible plants. During our investigation, the shift cultivation land and nearby forests have almost completely been transformed into rubber plantation. We found the rice fields were rented by the businessman to grow banana, chili, watermelon, kidney bean, and some other cash crops almost during the whole year. The original rice fields, which are normally full of water and an important wetland for many creatures, have now become relatively dried farm lands. The decrease areas of rice paddy caused severe loss of wetland habits, biodiversity, and cultural diversity in Jiangcheng County. For example, Brasenia schreberi J.F. Gmel. could be very easily found at the rice field and other wetland area and had some semi-cultivation practice [47], while it almost disappeared because of the loss of rice fields and change of land use for cash crops. Moreover, among the interviewed 109 villagers, only 27 respondents knew still how to eat this species. These were all elder people with an average age of 57.5 years. This result suggests the younger generation have already lost the traditional knowledge about this edible species, due to the rapid decrease and shrink of wetland habitats. Thus, we highlight that more conservation concern and efforts should also be paid to the tropical wetland areas.

Although, the decrease of wild edible plants still happens because of environmental change and human negative effects, there are also case of edible species increases due to human cultural exchange. Dendrobium species are usually consumed as medicine and crushed freshly to treat scald disease by local Dai people [50]. While, Dendrobium species are famous and expensive traditional tonic medicine to rescue lives by Han people in the middle and east part of China. In the 1990s, there was a huge increase in demand of wild Dendrobium plants, and the related cultivation industry boomed in Southwest China for its suitable climate and lower investments. Local people learned that Dendrobium species not only have external and medicinal use but also could be cooked and eaten for health benefits during their communication with the outside businessman. There were 107 orchid species sold at Xishuangbanna market with Dendrobium plants as the main traded species [51]. The culture exchange enriched the dish list of the local people, while it also contributed the increase harvesting and conservation pressure of endangered
Dendrobium species because of the preference of wild products by the locals. Our results thus indicate that culture exchange could increase the culture diversity but might have more conservation pressure on endangered species, and ethnobotanical data about the use frequency and consumption demands of the endangered edible species should be included and considered when we evaluate the conservation status of the threatened species.

\section{Important role of traditional knowledge for local communities and forest ecosystem services}

The forest plays an important role for local communities. Local Dai people have a well-known proverb saying that only where there is fine forest, there is water, farming land, food, and people can thrive. This classic ecological belief ranked the forest in an extremely high position, and made a positive contribution to the biodiversity conservation in this region $[52,53]$. Based on the guidelines from specifications for assessment of forest ecosystem services in China [54], the estimated total value of forest ecosystem services in Pu'er City was 247,785 billion yuan per year, with the per unit area value of forest ecological service at 85,500 yuan per hectare per year [55]. These assessments were necessarily very simplified, usually focusing on a few, easily quantified services, and failed to include the services which are of most importance to local people and could therefore lead to incorrect policy decisions [56]. Jiangcheng County's forest cover increased rapidly from 43 to $68 \%$ during 1997 to 2018, according to the public data from the local government [7]. The availability of wild edible plants obtained from the forest, however, seems to have decreased according to our result and the description by the elder informants. Globally, the Aichi Biodiversity Target 11 (to protect at least 17 percent of terrestrial area by 2020) has been exceeded for forest ecosystems, but deforestation and forest degradation continue to take place at alarming rates and contribute significantly to the ongoing loss of biodiversity [57].

Therefore, on one hand, we suggested that we should equally evaluate the quantity and quality of the forest cover rate, and pay more attention to the negative effects of mono-culture forest plantations, such as rubber, on the traditional knowledge conservation and inheritance. On the other hand, ethnobotanical data on the value of the forest for providing the wild edible plants and other non-timber forest products to the local communities as well as the feedback effect from traditional knowledge and cultural diversity to forest conservation should be added into the specifications for assessment of forest ecosystem services. 


\section{Traditional cultivated plant genetic resources and diversified agriculture}

Local ethnic groups have a long tradition of introducing their preferred wild plants into farm lands and homegardens. The cultivated wild species are very important plant genetic resources (PGR) for the development of cash crops. Local Dai communities, cultivated 204 species for edible, medicinal, ornamental, and religious purposes, have a very close relationship with the formation and development of PGRs and play an important role in the conservation and utilization of PGRs [58].The UN's intergovernmental panel on climate change (IPCC) in Geneva issued a special report on climate change and land, pointing out that human activities and climate change will place land resources under huge pressure and that sustainable land and forest management, could prevent and reduce land degradation, maintain land productivity, mitigate the adverse effects of climate change to some extent, and conserve the precious land and ecosystems at the same time [59]. A recent discovery revealed that altering the cropping pattern from intensive monoculture to diversified agriculture, could help to withstand the climate change, protect vital wildlife, and alleviate the long-term loss of biodiversity outside natural protected areas in the future [60]. Besides, increasing plant species diversity could promote beneficial trophic interactions between insects and plants, ultimately contributing to increased ecosystem services [61].

Thus, we suggested that more wild edible plants could be introduced and cultivated in the nearby protected areas, farming land, rubber forest, tea plantations and village owned forest, homegardens, and any suitable sites to build corridors or ex situ reserve areas for some important, rare, medicinal, and edible plants, conserve more plant genetic resources and establish a diversified agriculture. Moreover, modern plantation technology should also be updated, and the cultivation and domestication of some preferred wild edible plants should be strengthened by cooperating with some food industries to reduce field collection, increase economic income and contribute to the sustainable development of local communities.

Top 30 wild edible plants for better conservation, understanding, and sustainable utilization in China, Laos, and Vietnam trans-boundary region

Besides the threats from climate change, plantation and livelihood transformation, over-harvesting and alarming loss of traditional knowledge, the local people also have to face human-elephant conflict for there have around 44 wild Asian elephant (Elephas maximus) individuals in Jiangcheng County (Fig. 7). With the potential increasing of elephant's population and expansion of its distribution, human-elephant conflict would be more serious due to continuous insufficient food, habitat loss, and fragmentation [32, 62, 63]. The wild plants are important and reliable food sources both for human and elephant. Among the reported 240 forage plants for wild Asian elephant in Southwest China [64], there are at least 44 overlapping wild edible plants both for human and elephant in Jiangcheng County. Thus, local ethnic people might have higher accident risk with wild Asian elephant

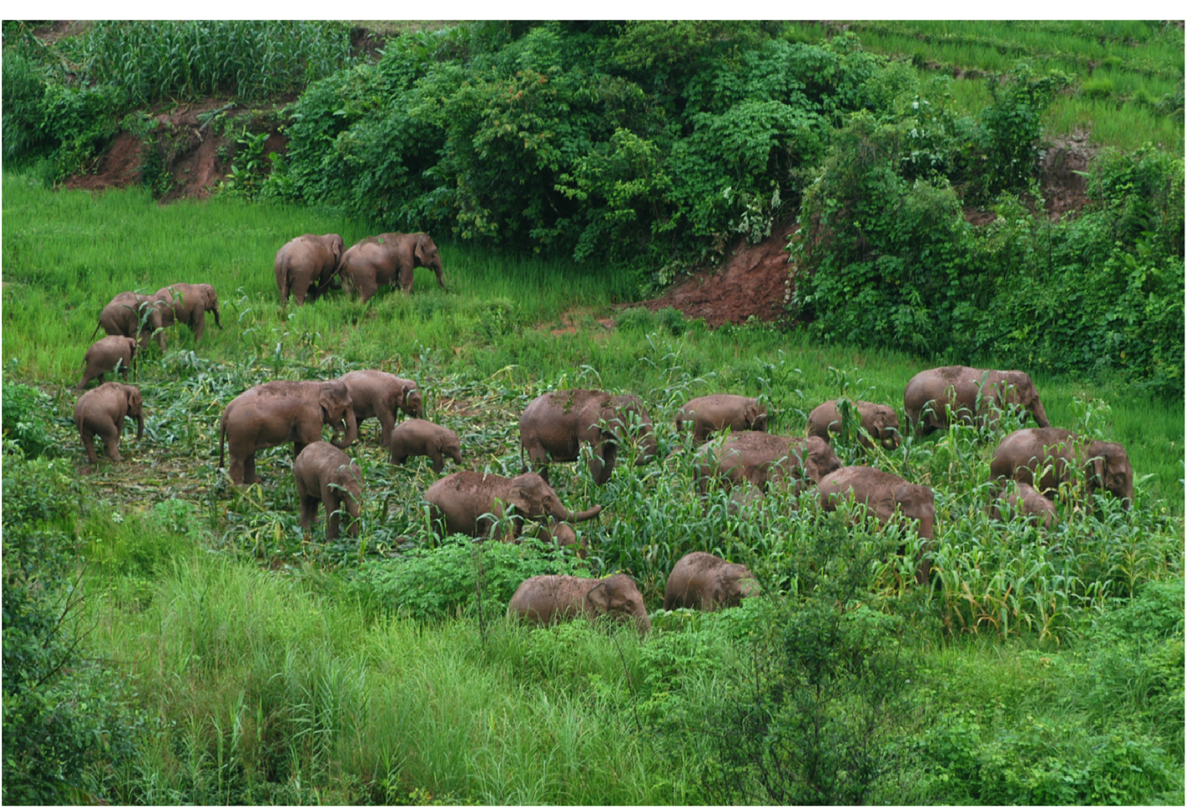

Fig. 7 A group of Wild Asian elephants feasting the corn and rice cultivated by local villagers nearby Jiangcheng County, Southwest China. Photographed by Mr. Shishun Zhou 
when they are both trying to harvest the same or similar wild edible plants at the same time. Nevertheless, establishing a food source base with fast-growing, and high biomass indigenous plants has proven to be one of the effective ways to solve this problem [65]. However, how to choose more suitable plants to introduce and cultivate in the elephant food source base still lacks practice and research data.

With limited land and investments, it is difficult to overcome all these mentioned problems, but we could use a multidimensional way to solve or minimize these issues. Based on our ethnobotanical survey, the data from threatened species list of China's Higher Plants and the IUCN Red List, the published food plant list for Asian Elephant, the Subject Database of China Plant and the calculated UV score, the top 30 most important wild edible plants (Table 5) were identified and recommended to be further cultivated and expanded in some local villages. These highlighted plants include 15 threatened or endangered species, 17 species with UV value over 0.9 and 19 species consumed by both humans and elephants. The environmental, cultural, and religious benefits of the forest are generally recognized by the local people [66]. By learning the ethnobotanical

Table 5 The top 30 most important wild edible plants recommended for cultivation, conservation, and sustainable use

\begin{tabular}{|c|c|c|c|c|c|c|}
\hline Family name & Scientific name & TSLCHPa $^{a}$ & NPLC ${ }^{\mathbf{b}}$ & $\mathrm{IUCN}^{c}$ & Elephant $^{d}$ & $u^{e}$ \\
\hline Anacardiaceae & Mangifera siamensis Warbg. ex Craib & EN & & & & 1.00 \\
\hline Anacardiaceae & Mangifera sylvatica Roxb. & EN & 2 & EN & Y & 0.94 \\
\hline Anacardiaceae & Spondias pinnata (L. F.) Kurz & & & & Y & 0.94 \\
\hline Apocynaceae & Amalocalyx microlobus Pierre & & & & Y & 0.98 \\
\hline Araliaceae & Panax zingiberensis C.Y. Wu \& K.M. Feng & EN & 1 & EN & & 0.14 \\
\hline Arecaceae & Caryota obtusa Griffith & VU & 2 & & Y & 0.49 \\
\hline Bignoniaceae & Mayodendron igneum (Kurz) Kurz & & & & Y & 0.99 \\
\hline Bignoniaceae & Oroxylum indicum (L.) Bentham ex Kurz & & & & Y & 0.97 \\
\hline Cabombaceae & Brasenia schreberi J.F. Gmel. & $C R$ & 1 & $C R$ & & 0.25 \\
\hline Cycadaceae & Cycas pectinata Buchanan-Hamilton & VU & 1 & VU & Y & 0.12 \\
\hline Dilleniaceae & Dillenia indica $\mathrm{L}$. & EN & & & Y & 0.83 \\
\hline Elaeocarpaceae & Elaeocarpus austroyunnanensis $\mathrm{Hu}$ & VU & & & & 0.45 \\
\hline Euphorbiaceae & Baccaurea ramiflora Loureiro & & & & Y & 0.99 \\
\hline Fabaceae & Acacia pennata (L.) Willd. & & & & Y & 0.99 \\
\hline Fabaceae & Bauhinia variegata var. candida (Roxb.) Voigt & & & & Y & 0.99 \\
\hline Menispermaceae & Parabaena sagittata Miers & & & & Y & 1.00 \\
\hline Moraceae & Ficus auriculata Lour. & & & & Y & 0.93 \\
\hline Moraceae & Ficus virens Aiton & & & & Y & 0.93 \\
\hline Moraceae & Morus alba L. & & & & Y & 0.93 \\
\hline Orchidaceae & Dendrobium chrysanthum Wall. ex Lindl. & VU & 1 & VU & & 0.52 \\
\hline Orchidaceae & Dendrobium crepidatum Lindl. ex Paxton & EN & 1 & EN & & 0.51 \\
\hline Orchidaceae & Dendrobium cucullatum R. Br. ex Lindl. & VU & & & & 0.52 \\
\hline Orchidaceae & Dendrobium devonianum Paxton & EN & 1 & EN & & 0.51 \\
\hline Poaceae & Dendrocalamus hamiltonii Nees \& Arn. ex Munro & & & & Y & 1.00 \\
\hline Poaceae & Pleioblastus amarus (Keng) Keng f. & & & & Y & 1.00 \\
\hline Polygonaceae & Fagopyrum dibotrys (D. Don) Hara & & & & Y & 0.98 \\
\hline Rutaceae & Zanthoxylum myriacanthum var. pubescens (C.C. Huang) C.C. Huang & VU & & & & 0.19 \\
\hline Solanaceae & Solanum torvum Swartz & & & & Y & 0.96 \\
\hline Lamiaceae & Gmelina arborea Roxb. & VU & & & & 0.36 \\
\hline Zingiberaceae & Etlingera yunnanensis (T. L. Wu \& S. J. Chen) R. M. Smith & VU & 2 & & & 0.20 \\
\hline
\end{tabular}

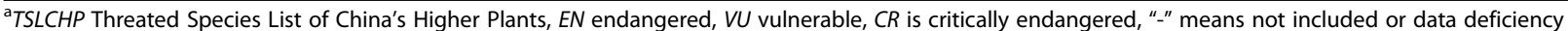
${ }^{\mathrm{b}} \mathrm{NPLC}$ National Protection level in China

'IUCN is the IUCN Red List of Threatened Species

${ }^{\mathrm{d}}$ Asian elephant forage plants; $Y$ yes

eUV use value 
knowledge from the ethnic groups and encouraging them to cultivate more plants, especially the endangered species, in the community land and individual households retained forest, as well as their homegardens could open a new channel for connecting the fragmented forest as a whole, then contributing to conservation and the sustainable use of natural resources.

Furthermore, from better protection of wild edible plants view, there is urgent need for policymakers to enhance the government coordination in this transboundary region $[67,68]$, and reinforce the monitoring and management of rare or endangered plants traded in local markets, to popularize the biodiversity conservation laws and to promote the awareness of the value of traditional knowledge. From the sustainable utilization and development of wild edible plants view, local governments could continue to make their three times per month's traditional market day (every 1st, 11th, 21st of each month) more famous of typical ethnic culture characters by encouraging local ethnic groups to sell more cultivated wild plants there. The trans-boundary good trade fair would be another platform for local communities to demonstrate their unique culture and to increase the nationalities' self-identification, then contribute to the conservation and inheritance of traditional knowledge for the trans-boundary ethnic groups.

\section{Conclusion}

An ethnobotanical study on wild edible plants used by three trans-boundary ethnic groups was conducted in Jiangcheng County, Pu'er City, Southwest China. A total of 211 wild edible plants and their traditional knowledge were documented in this study. Our results show that three trans-boundary Dai, Hani, and Yao people have plentiful traditional knowledge on the utilization of wild edible plants with diversified eating parts, preparation methods, and use purposes. Local people not only collect the edible plants from wild, but also cultivated and sold them in the markets. However, many of these wild edible plants were only frequently mentioned by the elder informants and there is an alarming risk of losing the traditional knowledge among younger generations. Endangered plants distributed at the wetland or sold at the market, such as Brasenia schreberi J.F. Gmel., Panax zingiberensis C.Y. Wu \& K.M. Feng, and Dedrobium species, deserve more conservation efforts. Based on our results, the top 30 most important wild edible plants were highlighted to be further cultivated and expanded in some local villages.

In conclusion, wild edible plants play an important role in local people's daily life, and the ethnobotanical information of the wild edible plants collected from ethnic groups could provide key scientific data to promote the traditional cultural value among the young generation and relief the stress of human-environment conflict. By referring to the traditional knowledge from the ethnic groups and encouraging them to make a diversified cultivation of wild edible plants in the community land and individual households, as well as their homegardens could launch a new bridge for wild plants to be more profitable cash crops, contribute to the sustainable use of natural resources, and conserve the endangered species in this trans-boundary region.

\section{Acknowledgements \\ Prof. Kyle Tomlinson and Dr. Lin Wang from Xishuangbanna Tropical Botanical Garden, Chinese Academy of Sciences were thanked for their technical guidance for the data analysis and figure preparation. Prof. Ahimsa Campos Arceiz was special thanked for his contribution to revise the language of this manuscript. The authors are grateful to the local government staff and villagers in Jiangcheng County for their help during the field survey.}

\section{Authors' contributions}

$\mathrm{RL}$ and $\mathrm{HBH}$ conceived and designed the study. LS and RCQ provide financial and academic instructions. YLC, SSZ, and RL conducted data collection and analysis. SSZ identified wild edible plants. RL, YLC, and HBH interpreted and wrote the draft manuscript. All authors read and approved the final manuscript.

\section{Funding}

This work was co-financed by the Southeast Asia Biodiversity Research Institute, Chinese Academy of Sciences (grant number Y4ZK111B01), by a project of the Lancang-Mekong Cooperation (LMC) Special Fund (Biodiversity Monitoring and Network Construction along Lancang-Mekong River Basin project, No. Y8GK041B01), the CAS 135 program (No. 2017XTBG-F03), and National Natural Science Foundation of China (No. 32000251).

\section{Availability of data and materials}

All data generated or analyzed during this study are included in this published article.

\section{Ethics approval and consent to participate}

Not applicable.

\section{Consent for publication}

Not applicable.

\section{Competing interests}

The authors declare that they have no competing interests.

\section{Author details \\ ${ }^{1}$ Agriculture Service Center, Zhengdong Township, Pu'er City 665903, Yunnan, China. ${ }^{2}$ Southeast Asia Biodiversity Research Institute, Chinese Academy of Sciences \& Center for Integrative Conservation, Xishuangbanna Tropical Botanical Garden, Chinese Academy of Sciences, Mengla 666303, Yunnan, China. ${ }^{3}$ University of Chinese Academy of Sciences, Beijing 100049, China. ${ }^{4}$ CAS Key Laboratory of Tropical Forest Ecology,Xishuangbanna Tropical Botanical Garden, Chinese Academy of Sciences, Menglun 666303, Yunnan, China. ${ }^{5}$ CAS Key Laboratory of Tropical Plant Resources and Sustainable Use, Xishuangbanna Tropical Botanical Garden, Chinese Academy of Sciences, Mengla 666303, Yunnan, China.}

Received: 8 July 2020 Accepted: 17 October 2020

Published online: 27 October 2020

\section{References}

1. Myers N, Mittermeier RA, Mittermeier CG, da Fonseca GAB, Kent J. Biodiversity hotspots for conservation priorities. Nature. 2000;403(6772):8538. https://doi.org/10.1038/35002501.

2. Mason N, Ward M, Watson JEM, Venter O, Runting RK. Global opportunities and challenges for transboundary conservation. Nat Ecol Evol. 2020;4(5): 694-701. https://doi.org/10.1038/s41559-020-1160-3. 
3. He Y. A preliminary survey of the cross-border ethnic groups in China and Vietnam. Chinese National Expo. 2019;03:13-4.

4. Huang X. On the identification of Sino-Laos cross-border ethnic group and their characteristics. J Guangxi University for Nationalities. 2006;28(3):85-8.

5. Qiang JY, Tao C, Zi YW, Qi LP. Pu'er City biodiversity status and conservation. Int J Ecol. 2017;6(3):140-5.

6. The Compilation Committee. The annals of Jiangcheng Hani and Yi Autonomous County. Kunming, Yunnan, China: Yunnan People's Publishing House; 1989.

7. The Yearbook Editor Committee. The yearbook of Jiangcheng Hani and Yi Autonomous County. Dehong, Yunnan, China: Dehong Ethnic Publishing House; 2018.

8. Xu YK, Liu HM. Tropical wild vegetables in Yunnan, China. Beijing: Science Press; 2002.

9. Alam MK, Rana ZH, Islam SN, Akhtaruzzaman M. Comparative assessment of nutritional composition, polyphenol profile, antidiabetic and antioxidative properties of selected edible wild plant species of Bangladesh. Food Chem. 2020;320. https://doi.org/10.1016/j.foodchem.2020.126646.

10. Bharucha Z, Pretty J. The roles and values of wild foods in agricultural systems. Philos Trans R Soc B-Biol Sci. 2010;365(1554):2913-26. https://doi. org/10.1098/rstb.2010.0123.

11. Turner NJ, Luczaj LJ, Migliorini P, Pieroni A, Dreon AL, Sacchetti LE, et al. Edible and tended wild plants, traditional ecological knowledge and agroecology. Crit Rev Plant Sci. 2011;30(1-2):198-225. https://doi.org/10. 1080/07352689.2011.554492.

12. Kuhnlein H EB, Spigelski D. Indigenous peoples' food systems. Rome,Italy: FAO, Centre for Indigenous People's Nutrition and Environment; 2009

13. Uprety Y, Poudel RC, Shrestha KK, Rajbhandary S, Tiwari NN, Shrestha UB, et al. Diversity of use and local knowledge of wild edible plant resources in Nepal. J Ethnobiol Ethnomed. 2012;8. https://doi.org/10.1186/1746-4269-8-16.

14. Ong HG, Kim YD. The role of wild edible plants in household food security among transitioning hunter-gatherers: evidence from the Philippines. Food Secur. 2017;9(1):11-24. https://doi.org/10.1007/s12571-016-0630-6.

15. Yang J, Chen WY, Fu Y, Yang T, Luo XD, Wang YH, et al. Medicinal and edible plants used by the Lhoba people in Medog County, Tibet, China. J Ethnopharmacol. 2020;249. https://doi.org/10.1016/j.jep.2019.112430.

16. Cruz-Garcia GS, Price LL. Weeds as important vegetables for farmers. Acta Soc Bot Pol. 2012:81(4):397-403. https://doi.org/10.5586/asbp.2012.047.

17. Delang CO. Not just minor forest products: the economic rationale for the consumption of wild food plants by subsistence farmers. Ecol Econ. 2006; 59(1):64-73. https://doi.org/10.1016/j.ecolecon.2005.10.006.

18. He T. Wild vegetable resources in Pu'er City. In: Forest by-product and Speciality in China, vol. 3; 2009. p. 84-7.

19. Tao C. A study on edible flower resources and application in Pu'er, Yunnan province. J Puer Univ. 2018;34(6):1-8.

20. Maiti P. Global climate change and its effects on biodiversity. Biodivers J. 2016;7(3):311-8

21. Stuart Chapin F III, Díaz S. Interactions between changing climate and biodiversity: shaping humanity's future. PNAS. 2020;117(12):6295-6. https://doi.org/10.1073/pnas.2001686117

22. Corlett RT. Plant diversity in a changing world: status, trends, and conservation needs. Plant Diversity. 2016;38(1):10-6. https://doi.org/10.1016/ j.pld.2016.01.001.

23. Barnosky AD, Matzke N, Tomiya S, Wogan GOU, Swartz B, Quental TB, et al. Has the earth's sixth mass extinction already arrived? Nature. 2011;471(7336): 51-7. https://doi.org/10.1038/nature09678.

24. Hu HB, Liu W, Cao M. Impact of land use and land cover changes on ecosystem services in Menglun, Xishuangbanna, Southwest China. Environ Monit Assess. 2008;146(1-3):147-56. https://doi.org/10.1007/s10661-0070067-7.

25. Li H, Ma Y, Aide TM, Liu W. Past, present and future land-use in Xishuangbanna, China and the implications for carbon dynamics. For Ecol Manag. 2008;255(1):16-24. https://doi.org/10.1016/.jforeco.2007.06.051.

26. Hemmavanh $C, Y e$ Y, Yoshida A. Forest land use change at trans-boundary Laos-China biodiversity conservation area. J Geogr Sci. 2010;20(6):889-98. https://doi.org/10.1007/s1 1442-010-0818-1.

27. Liu WJ, Hughes AC, Bai Y, Li Z, Mei C, Ma YX. Using landscape connectivity tools to identify conservation priorities in forested areas and potential restoration priorities in rubber plantation in Xishuangbanna, Southwest China. Landsc Ecol. 2020;35(2):389-402. https://doi.org/10.1007/s10980-01900952-2.
28. He JW, Zhang RF, Lei QY, Chen GX, Li KG, Ahmed S, et al. Diversity, knowledge, and valuation of plants used as fermentation starters for traditional glutinous rice wine by Dong communities in Southeast Guizhou, China. J Ethnobiol Ethnomed. 2019;15. https://doi.org/10.1186/s13002-0190299-y.

29. Salinitro M, Vicentini R, Bonomi C, Tassoni A. Traditional knowledge on wild and cultivated plants in the Kilombero Valley (Morogoro region, Tanzania). J Ethnobiol Ethnomed. 2017;13. https://doi.org/10.1186/s13002-017-0146-y.

30. Li DL, Xing FW. Ethnobotanical study on medicinal plants used by local Hoklos people on Hainan Island, China. J Ethnopharmacol. 2016;194:358-68. https://doi.org/10.1016/j.jep.2016.07.050.

31. Uchida K, Kamura K. Traditional ecological knowledge maintains useful plant diversity in semi-natural grasslands in the Kiso region. Japan Environ Manage. 2020;65(4):478-89. https://doi.org/10.1007/s00267-020-01255-y.

32. Zhu GF, Zheng X, Lv T, Jiang GL, Tang YJ, Li ZL, et al. A dynamics analysis of Xishuangbanna-Puer Asian elephant population. For Construct. 2019;06:85-90.

33. International Society of Ethnobiology. ISE code of Ethics. 2008.

34. Pei SJ, Long CL. Applied ethnobotany. Kunming, Yunnan, China: the Nationalities Publishing House of Yunnan; 1998.

35. Luo BS, Liu B, Zhang HZ, Zhang HK, Li X, Ma L, et al. Wild edible plants collected by Hani from terraced rice paddy agroecosystem in Honghe prefecture, Yunnan, China. J Ethnobiol Ethnomed. 2019;15(1). https://doi. org/10.1186/s13002-019-0336-x.

36. Chase MW, Christenhusz MJM, Fay MF, Byng JW, Judd WS, Soltis DE, et al. An update of the angiosperm phylogeny group classification for the orders and families of flowering plants: APG IV. Bot J Linnean Soc. 2016;181(1):120. https://doi.org/10.1111/boj.12385.

37. The Plant List. http://www.theplantlist.org/. Accessed 30 August 2020.

38. International Union for Conservation of Nature. The IUCN red list of threatened species. Version 2015-3.

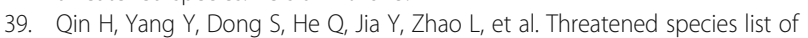
China's higher plants. Biodivers Sci. 2017;25(7):696-744. https://doi.org/10. 17520/biods.2017144.

40. National key protected wild plant lists (first and second batch). http://www. plant.csdb.cn/protectlist (2020). Accessed 8 June 2020.

41. Ong HG, Ling SM, Win TTM, Kang DH, Lee JH, Kim YD. Ethnobotany of wild medicinal plants used by the Müün ethnic people: a quantitative survey in southern Chin state, Myanmar. J Herb Med. 2018;13:91-6. https://doi.org/10. 1016/j.hermed.2017.09.006

42. Ladio AH, Lozada M. Comparison of wild edible plant diversity and foraging strategies in two Aboriginal communities of northwestern Patagonia. Biodivers Conserv. 2003;12(5):937-51. https://doi.org/10.1023/a: 1022873725432

43. Wu ZY, Li H. Colocasia in Flora of China. Beijing, China: Science Press; 1979. p. 67-8

44. Liu Y, Xue K, Xing D, Long C. Ethnobotanical survey on application of Colocasia gigantea in southern and southwestern China. J Plant Resour Environ. 2017; 26(2):118-20. https://doi.org/10.3969/j.issn.1674-7895.2017.02.18.

45. Zhang K, Gao C, Rao W, Yin H. Ethnobotanical study on medicinal herb market during Dragonboat festival in Pu'er, Yunnan, China. Bangladesh $J$ Bot. 2019;48(3):733-44.

46. Kang Y, Luczaj L, Kang J, Zhang S. Wild food plants and wild edible fungi in two valleys of the Qinling Mountains (Shaanxi, Central China). J Ethnobiol Ethnomed. 2013;9. https://doi.org/10.1186/1746-4269-9-26.

47. Xu YK, Tao GD, Liu HM, Yan KL, Dao XS. Wild vegetable resources and market survey in Xishuangbanna, Southwest China. Econ Bot. 2004;58(4):647-67.

48. Yu PH, Xu ZF, Huang YL. The study on traditional cultivated plants in Dai villages of Xishuangbanna. Acta Bot Yunnan. 1985;7(2):169-86.

49. Fu YN, Chen AG, Liu ZQ, Chen JY. Plant diversity and folk utilizable plants of swidden agroecosystem of tropical mountain. Chinese J Ecol. 2000;19(3):1-6.

50. National Administration of Traditional Chinese Medicine. Traditional Chinese Meteria Medica of Dai nationality. Shanghai, China: Shanghai Science and Technology Press; 2005.

51. Song Y, Lie Z, Willian S, Gao J. Characteristics of the orchid trade at public markets and implications for conservation in Xishuangbanna, Yunnan, China. Biodivers Sci. 2017;25(5):531-9. https:/doi.org/10.17520/biods.2017022.

52. Liu HM, Xu ZF, Xu YK, Wang JX. Practice of conserving plant diversity through traditional beliefs: a case study in Xishuangbanna, Southwest China. Biodivers Conserv. 2002;11(4):705-13. https://doi.org/10.1023/A: 1015532230442 
53. Xu ZF. Conservation of biodiversity and cultural diversity are two sides of a coin: Xishuangbanna Dai's ecological culture as an example. Biodivers Sci. 2015;23(1):126-30.

54. State Forestry Bureau of China. Specifications for assessment of forest ecosystem services Beijing, China: China Standard Press; 2008.

55. Wu J, Yang D, Yang GW. The estimated total value of forest ecosystem services in Pu'er City, Yunnan Province. Sci Technol Inf. 2018;16(10):250-1.

56. Corlett R. Biodiversity and ecosystem services: towards ecological security in tropical and subtropical East Asia. Biodivers Sci. 2018;26(7):766-74. https:// doi.org/10.17520/biods.2018020.

57. Food and Agriculture Organization of The United Nations. The state of the world's forests $2020 \mathrm{http}: / / \mathrm{www}$.fao.org/state-of-forests/2020/en/ (2020). Accessed 26 May 2020.

58. Long CL, Li ML. Status and conservation strategies of community plant genetic resources---a case study in Manlun, a Dai village in Xishuangbanna. Chinese Bull Bot. 2006;23(2):177-85.

59. Shukla PR, Skeg J, Calvo Buendia E, Masson-Delmotte V, Pörtner H-O, Roberts DC, et al. Climate change and land: an IPCC special report on climate change, desertification, land degradation, sustainable land management, food security, and greenhouse gas fluxes in terrestrial ecosystems; 2019.

60. Hendershot JN, Smith JR, Anderson CB, Letten AD, Frishkoff LO, Zook JR, et al. Intensive farming drives long-term shifts in avian community composition. Nature. 2020;579(7799):393-6. https://doi.org/10.1038/s41586020-2090-6.

61. Wan NF, Zheng XR, Fu LW, Kiær LP, Zhang Z, Chaplin-Kramer R, et al. Global synthesis of effects of plant species diversity on trophic groups and interactions. Nat Plants. 2020;6(5):503-10. https://doi.org/10.1038/s41477020-0654-y

62. Liu P, Dai J, Cao D, Li Z, Zhang L. Habitat suitability assessment for Asian elephant in Pu'er prefecture in the Yunnan province of China. Acta Ecol Sin. 2016;36(13):4163-70

63. Zhao Y, Jin K. Distribution, population, habitat status and population management of Asian elephant. World For Res. 2018;31(2):25-30.

64. Jiang Z, Li Z, Bao M, Chen M. The statistics and analysis of foraging plants species eaten by Asian elephant (Elephas maximus) in China. Acta Theriol. Sin. 2019:39(5):514-30; doi: https://doi.org/10.16829/.s/xb.150237.

65. Guo XM, Wang LX. Thoughts on the construction of Asian elephant food source base in Xishuangbanna. For Constr. 2019:6:30-3.

66. Zhang JQ, Mammides C, Corlett RT. Reasons for the survival of tropical forest fragments in Xishuangbanna, Southwest China. Forests. 2020;11(2). https://doi.org/10.3390/f11020159.

67. Choe $\mathrm{H}$, Thorne JH. Climate exposure of east Asian temperate forests suggests transboundary climate adaptation strategies are needed. Clim Chang. 2019;156(1-2):51-67. https://doi.org/10.1007/s10584-019-02493-8.

68. Santarem F, Saarinen J, Brito JC. Mapping and analysing cultural ecosystem services in conflict areas. Ecol Indic. 2020;110. https://doi.org/10.1016/j ecolind.2019.105943.

\section{Publisher's Note}

Springer Nature remains neutral with regard to jurisdictional claims in published maps and institutional affiliations.

Ready to submit your research? Choose BMC and benefit from:

- fast, convenient online submission

- thorough peer review by experienced researchers in your field

- rapid publication on acceptance

- support for research data, including large and complex data types

- gold Open Access which fosters wider collaboration and increased citations

- maximum visibility for your research: over $100 \mathrm{M}$ website views per year

At $\mathrm{BMC}$, research is always in progress.

Learn more biomedcentral.com/submissions 